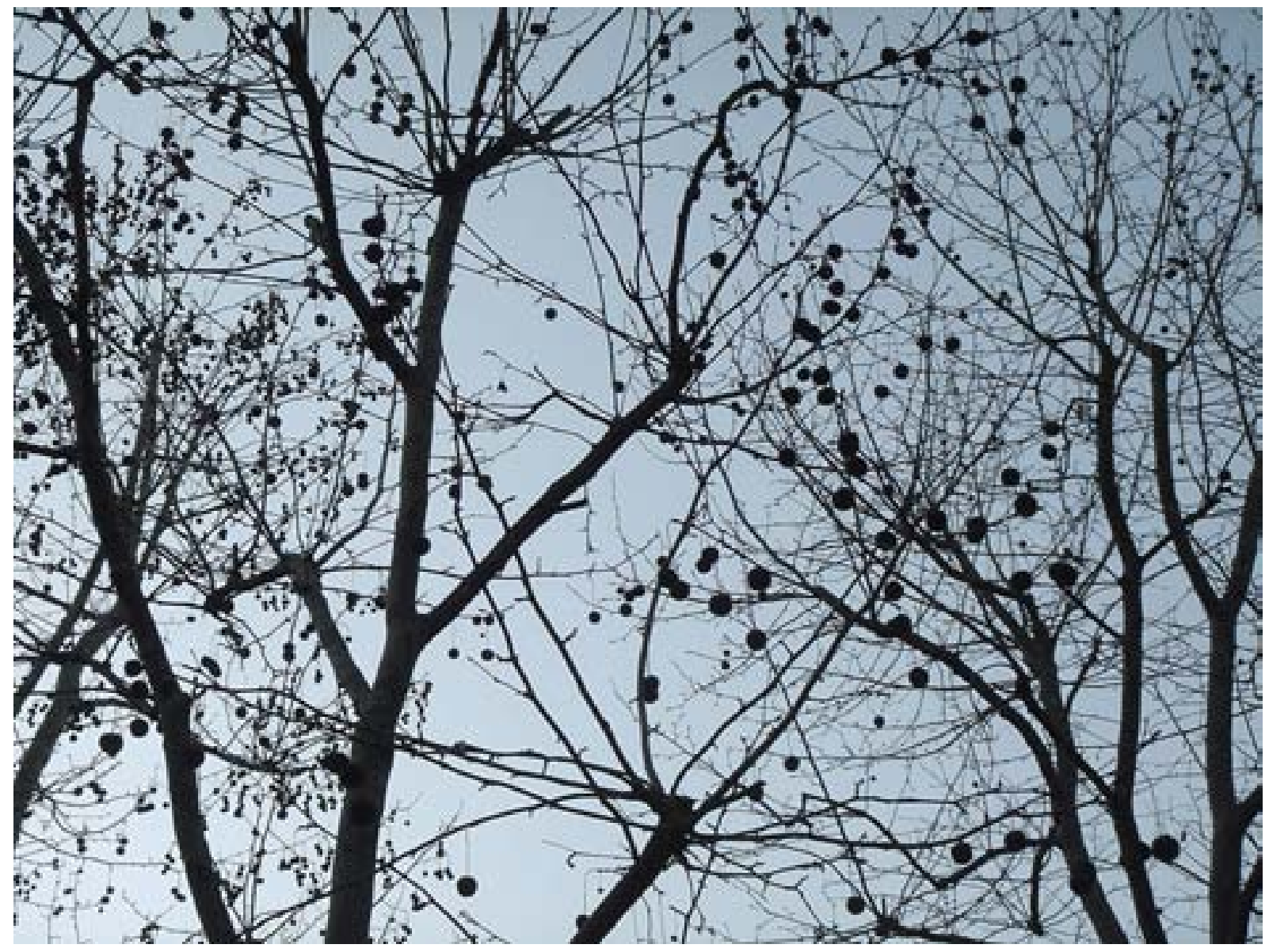




\section{Operaciones de efecto y mímesis: arquitectura naturalizada y naturaleza arquitectonizada Miguel Guitart}

\begin{abstract}
El arquitecto ha considerado la naturaleza como modelo durante siglos, trazando dos líneas generales en la aproximación al diseño arquitectónico: una que reinterpreta las estructuras naturales de manera directa, y otra que explora el potencial directo de los materiales naturales como forma de proponer nuevas estructuras y espacios. Mientras la primera da lugar a una presencia arquitectónica dado que su producción es visualmente inmediata y conceptualmente comprensible por un público mayoritario, la segunda, sin embargo, puede resultar menos común, al generar una serie de soluciones inesperadas debido a su aplicación más limitada a recursos o entornos puramente naturales que producen ejercicios de naturaleza arquitectónica.
\end{abstract}

\section{PALABRAS CLAVE}

natural, artificial, efecto, mímesis, estructura

\section{KEYWORDS}

Natural, Artificial, Effect, Mimesis, Structure
LA NATURALEZA COMO UN MODELO BÁsıco

\author{
"En la naturaleza más salvaje no sólo existe el material para la \\ vida más culta y una cierta anticipación del último resultado, \\ sino también el mayor refinamiento que el hombre pueda \\ nunca lograr". \\ Henry David Thoreau' \\ "El hombre viene de la naturaleza y a ella regresa". \\ Peter Zumthor ${ }^{2}$
}

La arquitectura, como ciencia constructiva del hábitat intelectual y físico del hombre, ha partido a menudo de la naturaleza como modelo básico. Al respecto, un período específico de gran interés tiene lugar entre los siglos XVIII y XX cuando, como indica Barry Bergdoll, "la

\begin{abstract}
Miguel Guitart
Doctor Arquitecto por la Escuela Técnica Superior de Arquitectura de la Universidad Politécnica de Madrid. Master in Architecture en el Graduate School of Design GSD de la Universidad de Harvard como becario J. W. Fulbright. Durante esos años, Guitart es profesor invitado en el Boston Architectural Center y participa en el programa de arquitectura Career Discovery del GSD de Harvard. Entre 2006 y 2014 es Profesor Asociado de Proyectos en la Escuela de Arquitectura de la Universidad Pontificia de Salamanca UPSAM, y entre 2013 y 2014 es Profesor Asociado de Proyectos de la Escuela de Ingeniería y Arquitectura de la Universidad de Zaragoza UNIZAR. Su trabajo es seleccionado para la exposición JAE Jóvenes Arquitectos de España en Madrid, Nueva York, Bruselas, Venecia, Estocolmo, París, Roma, Estados Unidos, Canadá y Latinoamérica, la Fundación Próxima y los Premios de Arquitectura de Mallorca. Su estudio Gimeno - Guitart recibe el ACSA Faculty Design Honorable Mention y el AZ People's Choice Award en 2017. Es autor de numerosos artículos en publicaciones internacionales como Journal of Architectural Education JAE, Cátedra Cerámica, TC Cuadernos, ZARCH, Future Arquitecturas y Arquitectura COAM. Actualmente es Clinical Associate Professor en la School of Architecture and Planning en la State University of New York at Buffalo (SUNY).
\end{abstract}

Fig. 01

Champ de Mars. París. Francia. 
investigación sobre mecanismos generadores de forma procedentes de la naturaleza [...] se inclinaron por formas afines a algunas leyes naturales de crecimiento con el fin de guiar su búsqueda por un vocabulario libre de la imitación de los estilos históricos"3. Tras la tesis planteada por el Abate Laugier en el siglo XVIII y las observaciones posteriores sobre el mundo natural por parte del francés Georges Buffon en su Histoire Naturelle (1749-1778), Bergdoll sugiere que en la última década del siglo XIX, Victor Horta y Henry van de Velde en Bruselas, Hector Guimard y René Binet en París, Antoni Gaudí en Barcelona, Hermann Obrist y August Endell en Munich, y Louis Sullivan en Chicago, entre otros muchos, exploraron de manera explícita la naturaleza como un modelo para la arquitectura con el fin de alejarse de un lenguaje predominantemente histórico (fig. 01).

Podríamos analizar una evolución de las leyes generadoras que subyacen bajo la diversidad de las formas naturales. La idea de que dichas formas puedan "engendrar un arte que pudiera equipararse en sí mismo con las fuerzas productivas de la naturaleza era una preocupación recurrente de arquitectos y teóricos convencidos del dicho, explorado inicialmente por Johann Wolfgang von Goethe y otros teóricos románticos alemanes, de que la naturaleza se caracterizaba por una unidad que subyacía bajo su variedad". Sin embargo, las investigaciones realizadas por Goethe apenas tuvieron repercusión alguna en la disciplina arquitectónica en la siguiente generación, hasta que fueron popularizadas por su discípulo y amigo Alexander von Humboldt en su serie de conferencias Cosmos en Berlín (1827-28) (figs. 02 y 03). El autor nos recuerda que en 1828 :

\footnotetext{
"Schinkel ayudó a Humboldt a decorar el interior del Schauspielhaus berlinés [...] para recibir la primera convención de científicos sobre la naturaleza. [...] [Algunos proyectos de] Schinkel implicaron diseños en los que una búsqueda de las formas primigenias de la arquitectura exploraban la novedad en un diálogo próximo a la tradición romántica de la morfología. [...] Treinta y cinco años después, Friedrich Adler celebraba la Bauakademie como una revisión de la idea de Goethe sobre la semilla original, así como un ímpetu por una nueva generación de investigación históriconatural y arquitectónica"s.
}

Para Schinkel el significado de la Bauakademie se fundamentaba tanto en su ornamentación en terra cotta como en su construcción en ladrillo: "uno no debe entender el término ornamento o decoración para acentuar la imitación de algo que se apoya fuera del objeto y de su esencia o de su idea fundamental"6. Este intenso intercambio de ideas se desarrolló principalmente tras la cercana y fructífera colaboración entre el científico Humboldt y el arquitecto Schinkel, ambos influidos por Goethe. De hecho, el escritor alemán había escrito Metamorfosis de las Plantas en 1790 como "la fuente de todo estudio y explicación de carácter morfológico"` (fig. 04). Bergdoll sostiene que para Goethe toda la historia natural previa se había concentrado en taxonomías formales de tipo superficial más que en lo que llamó la "economía interior" de la forma orgánica. "Goethe percibió los signos morfológicos de desarrollo en cada planta, y explicó las etapas en la evolución de las plantas, las cuales podían revelar la unidad generadora y formal del mundo natural ${ }^{8}$. En palabras de Schinkel: "La arquitectura es la continuación de la naturaleza en su actividad constructora. Esta actividad es canalizada a través de dicho producto natural: la raza humana". 


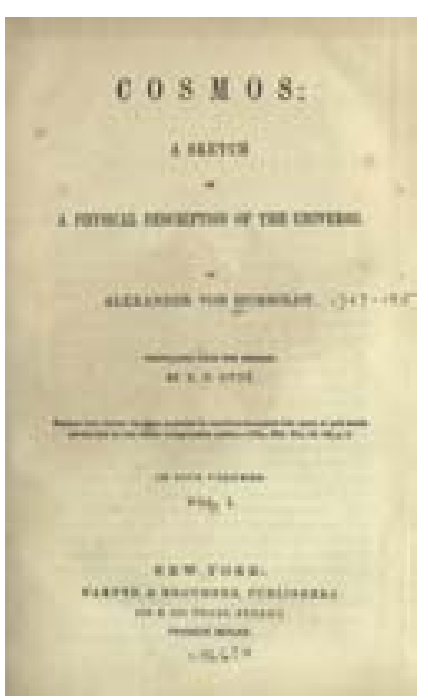

02

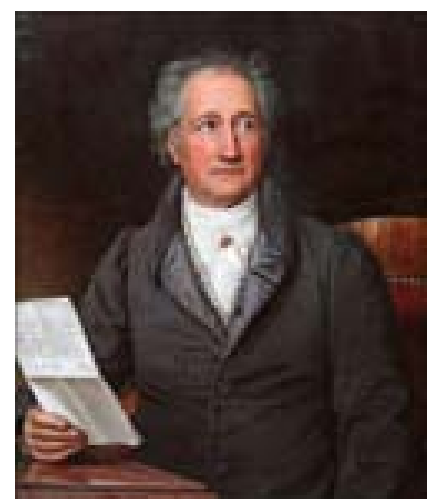

04

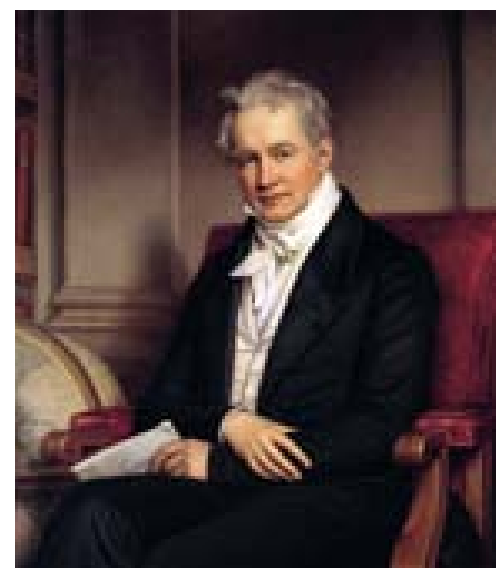

03

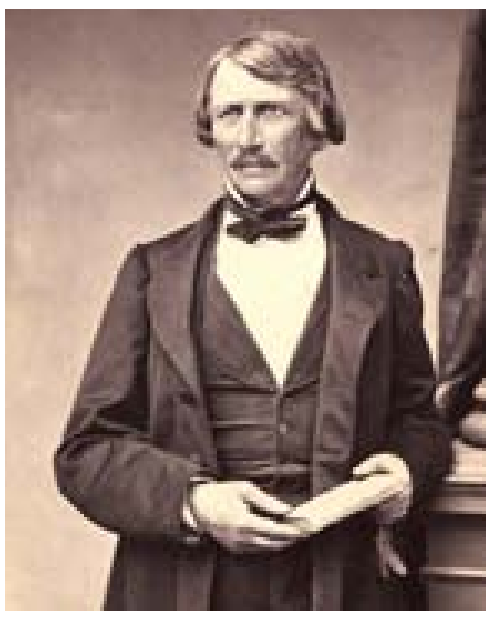

05

Posteriormente, otros dos autores merecen especial atención por su aproximación y comprensión del papel de la naturaleza en la configuración del medio construido: Gottfried Semper y Viollet-leDuc. Semper se inspiró en la visión perseverante de Humboldt acerca del estudio de la historia y de la naturaleza como "búsquedas paralelas de la verdad: "Encontramos que su resultado más noble e importante es un conocimiento sobre la cadena de conexiones por medio de la cual todas las fuerzas naturales están conectadas, haciéndose mutuamente dependientes unas sobre otras; $y$ es la percepción de estas relaciones que exalta nuestras visiones y ennoblece nuestros disfrutes"' "' (fig. 05). Eugène Emmanuel Viollet-le-Duc, por otra parte, escribió al final del siglo XIX que "la arquitectura como arte es una creación humana. Tal es nuestra inferioridad que, para alcanzar este tipo de creación, estamos obligados a proceder tal y como procede la naturaleza en las cosas que ella crea. Estamos obligados a emplear los mismos elementos y el mismo método lógico que la naturaleza; estamos obligados a observar las mismas transiciones"".

Inspirados por los intereses de Semper en las relaciones y conexiones naturales, así como en la defensa de los métodos de transición de la naturaleza estudiados por Viollet-le-Duc, los arquitectos

Fig. 02

Alexander von Humboldt. Portada de las conferencias Cosmos. 1866.

Fig. 03

Alexander von Humboldt.

Autor, Joseph Karl Stieler. 1843.

Fig. 04

Johann Wolfgang von Goethe.

Autor, Joseph Karl Stieler. 1828.

Fig. 05

Gottfried Semper, fotografiado en 1865. 
Fig. 06

Guaranty Building. Buffalo, New York. Arquitecto, Louis Sullivan.

\section{Fig. 07}

Guaranty Building. Buffalo, New York. Arquitecto, Louis Sullivan. Detalle de la cornisa.

Fig. 08

Ernst Haeckel. Prosobranchia. https://www.biodiversitylibrary.org/ item/40590\#page/5/mode/1up

Fig. 09

Ernst Haeckel. Monophiletischer Stammbaum der Organismen. Jena, Alemania. 1866. www.graphicine.com posteriores se interesaron de manera creciente en la idea de los conceptos unificadores en relación con la forma natural, a pesar de la creciente especialización de la ciencia y el "aumento de la fragmentación del orden natural que contemplaba”. Bergdoll insiste en esta observación al compartir un episodio sobre el discurso entre "la búsqueda para penetrar en las leyes subyacentes sobre la generación formal en la naturaleza y la búsqueda de una arquitectura libre de una investigación anticuaria", que relata del siguiente modo:

\footnotetext{
"[En los años 1860] El arquitecto Simon Claude Constant-Dufeux se suscribió a la doctrina del Eclecticismo definida por el filósofo Victor Cousin como reacción contra las estéticas idealistas francesas, en particular, bajo su axioma de la "Unidad en la Diversidad". Victor-Marie Ruprich-Robert convirtió la influyente instrucción oral de Constant-Dufeux en un método de enseñanza publicado ${ }^{12}$. [...] Ruprich-Robert fue uno de los muchos intermediarios entre la investigación sobre las ciencias naturales y la enseñanza del dibujo en el París de mediados de siglo [XIX] [...] Ruprich-Robert propuso en su lugar que el ornamento sirviera a los diseñadores a escapar del historicismo".
}

Estas aproximaciones a la exploración de los modelos naturales tuvo lugar en paralelo en Francia y Alemania a finales del siglo XIX. Una influencia mutua se desarrolló entre autores, científicos, intelectuales y arquitectos franceses y alemanes. $Y$ fue Louis Sullivan quien trasladó dichas visiones a América. Sullivan viajó de Chicago a París en julio de 1874. El arquitecto americano estaba particularmente interesado en la nueva escuela de investigación del ornamento y en la figura del académico Victor-Marie Ruprich-Robert, así como en sus manifiestos en materia de exploración ornamental como mecanismo para alejarse del historicismo. Sullivan escribió "Ornamento en arquitectura" en 1906, muy influido por el trabajo de Schinkel producido setenta años antes. La carrera de Sullivan se podría resumir como una concienciación gradual de la creciente coordinación entre estructura y ornamento. Un buen ejemplo es el Guaranty Building en Buffalo, Nueva York (1894), donde "toda superficie parecía literalmente crecer y florecer"13 (figs. 06 y 07).

Con el cambio de siglo, el biólogo y oceanógrafo alemán Ernst Haeckel había cautivado a toda una generación de artistas con imágenes de medusas, corales y criaturas microscópicas del océano, especialmente radiolarios (figs. 08 y 09). Bergdoll proporciona una detallada descripción de la influencia directa de Haeckel en la arquitectura de entonces.
"[...] La ausencia de una distinción clara entre los ámbitos animal y vegetal estaba entre los temas de investigación de Haeckel dentro de la miríada de nuevas especies de vida microscópica descubiertos en el mar y transformados en las espeluznantes láminas a color de su Kunstformen der Natur (18991904). [...] Tal vez ningún artista estuvo más fascinado con los descubrimientos de Haeckel que René Binet, cuya portada metálica de tres patas y 45 metros para la Exposition Universelle de 1900 [en París] era nada menos que una forma monumental de una de las phormocyrtida pubicadas por Haeckel en su Informe sobre los Radiolarios de 1887. [...] lgual que las esponjas y los corales del universo de Haeckel, [Binet] concibió una forma en la que estructura y decoración quedaban integrados, donde la estructura y el espacio se creaban 


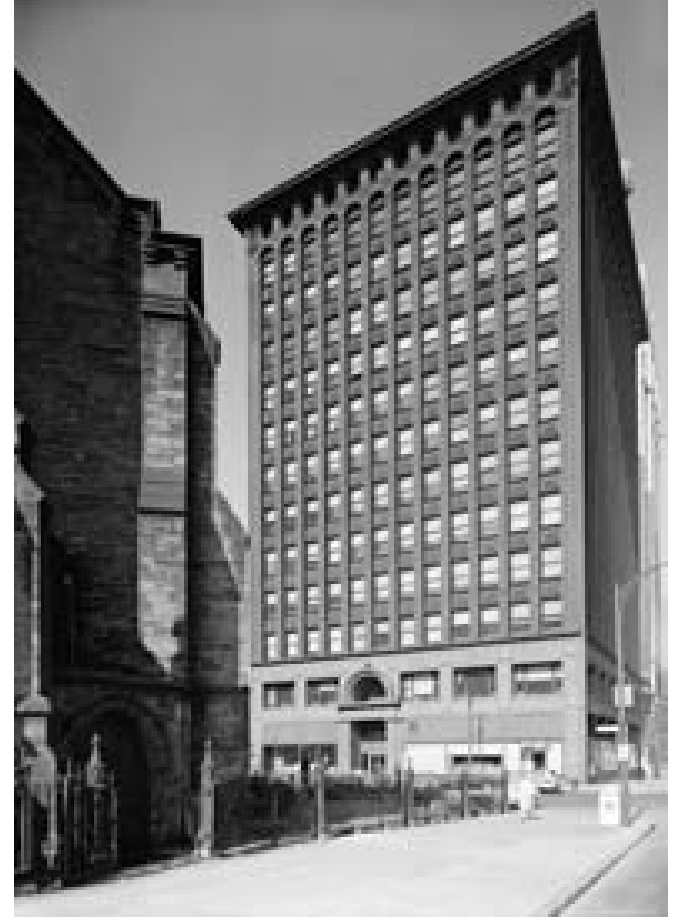

06

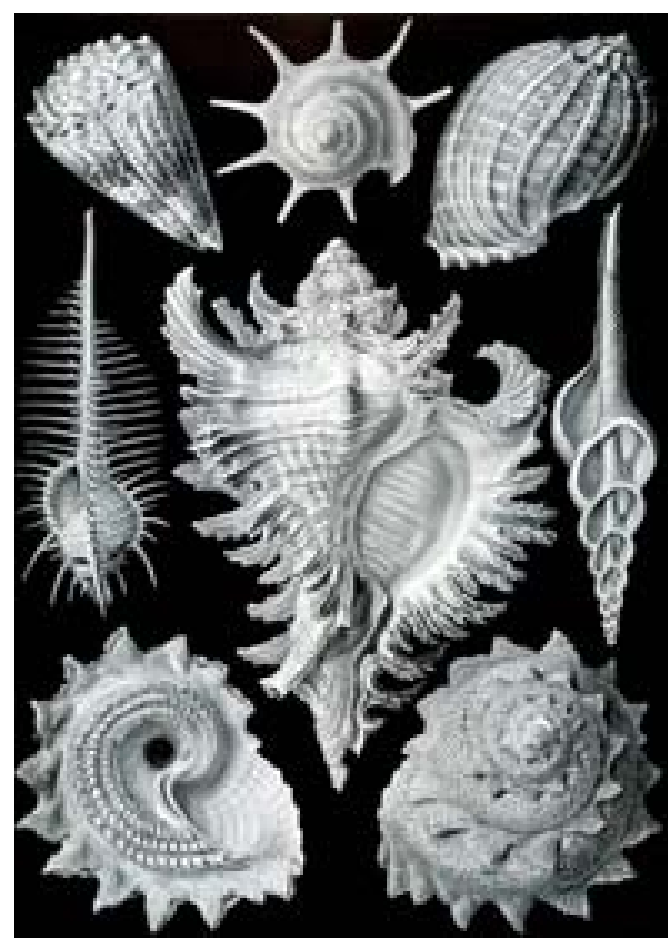

08

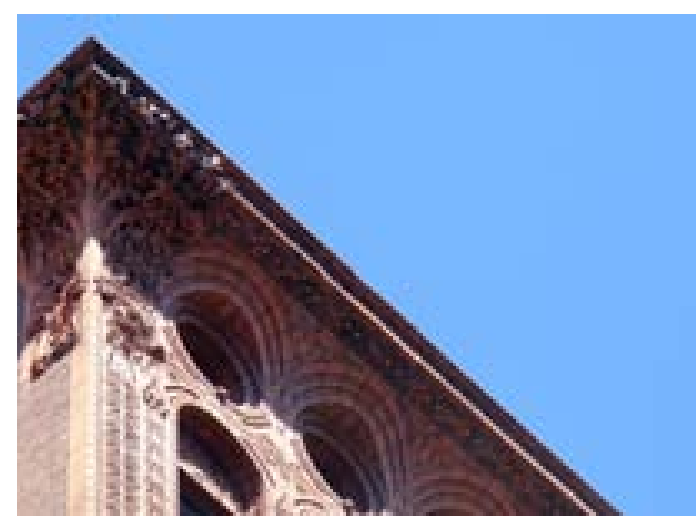

07

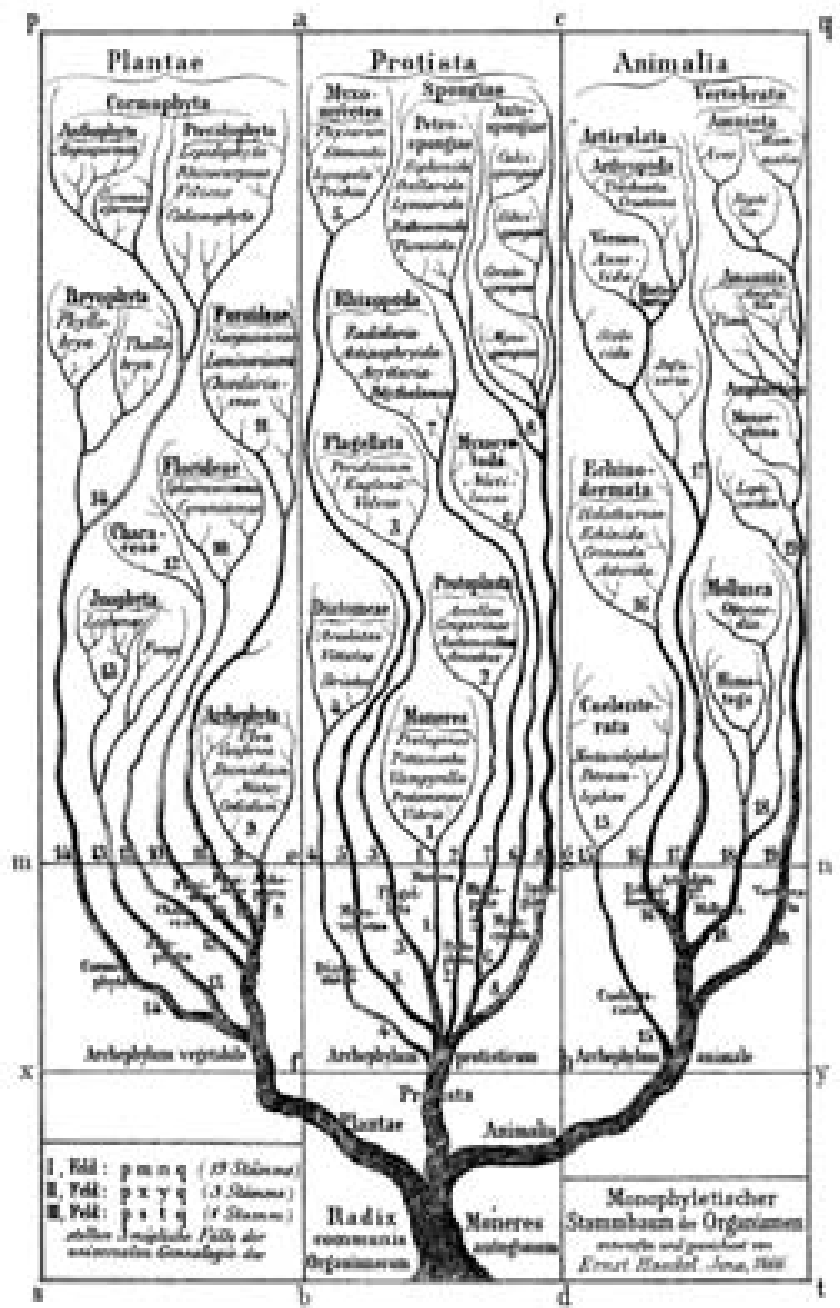




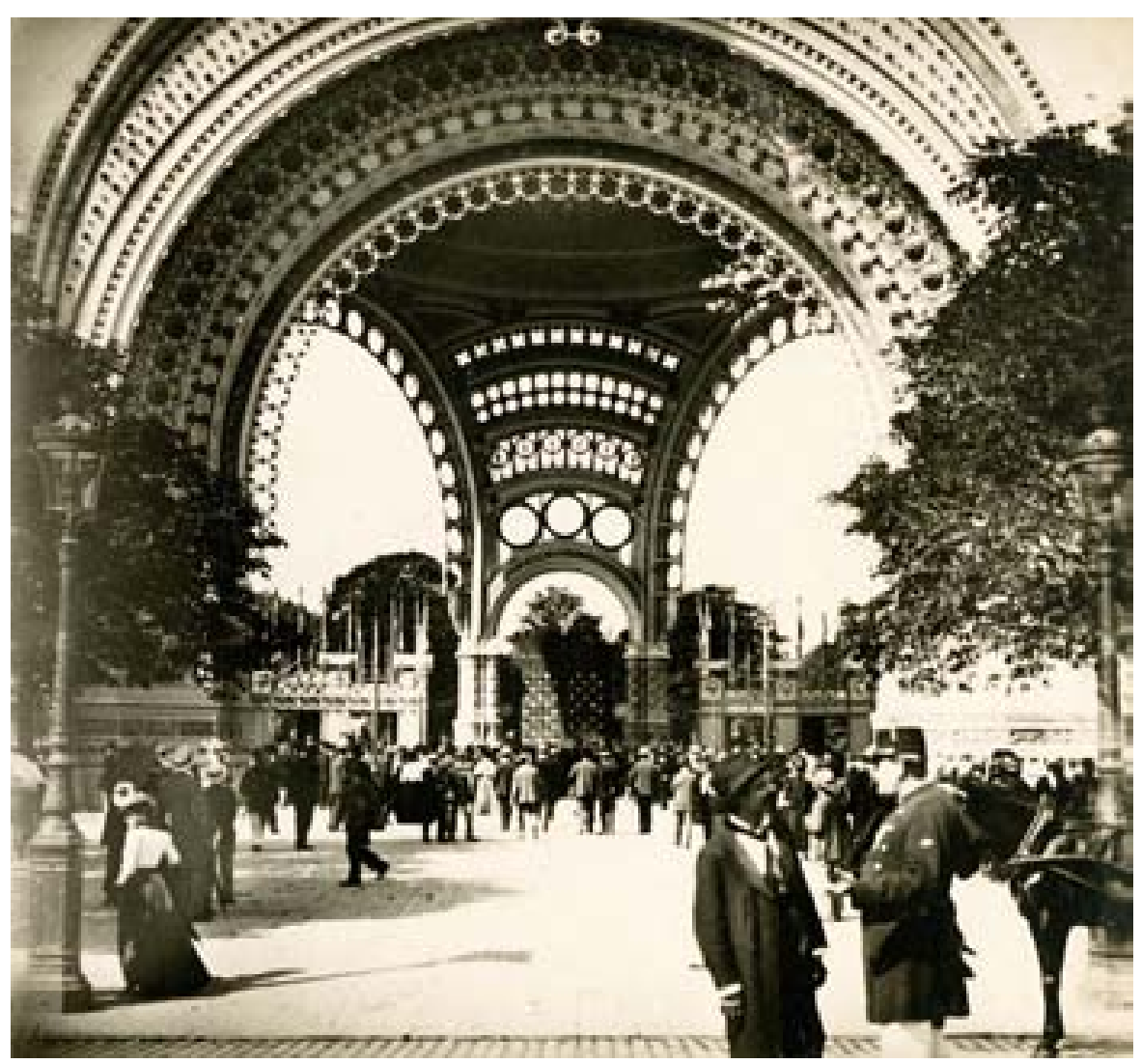

11

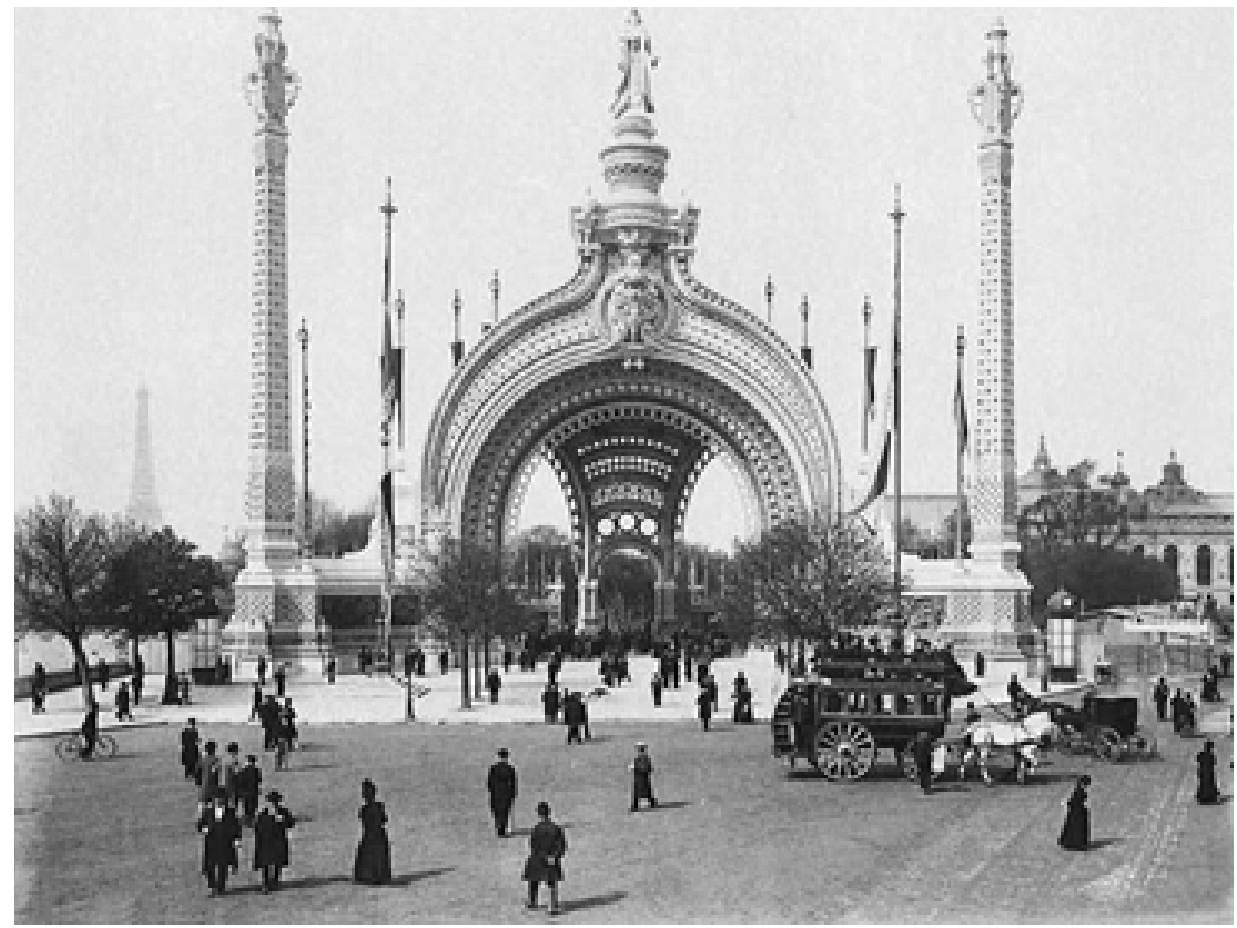


mutuamente ${ }^{14}$ (figs. 10 y 11). Durante casi una década Binet mantuvo una intensa correspondencia con Haeckel en Jena. [...] Binet insistía en que estas formas no serían la base para un nuevo estilo. Más bien, Binet pedía a los arquitectos "observar el gran laboratorio de la Naturaleza, siempre en movimiento, siempre en producción, sin un momento de descanso o duda".15 [...] El objetivo era animar a los estudiosos a conectar con la mayor de las ambiciones de Binet: "El esfuerzo del que deriva será retenido, categorizado y empleado por la razón que abarca un orden completo en los trabajos necesarios, y que dotará a la ejecución de dichos trabajos de un espíritu notable de unidad y método ${ }^{16}$. [...] En su fascinación por las similitudes entre células y cristales, compartida por Haeckel, Binet predice una de las fascinaciones centrales de la arquitectura del siglo XX -desde los Expresionistas alemanes de los años 20 a los Metabolistas de los años 60- por encontrar la forma de la abstracción arquitectónica en resonancia con los bloques constructivos del universo"17 (fig. 12).

Hoy día el desarrollo de la arquitectura mantiene su exploración de la naturaleza como generador de soluciones estructurales, materiales y espaciales. Una evolución inevitable ha conducido a la incorporación de nuevos materiales y técnicas, diversificando la conexión entre naturaleza y arquitectura. Se podría argumentar que la primera se ha mantenido principalmente como medio de la segunda, que a menudo se observa como artefacto. Sin embargo, esta distinción podría considerarse superficial e imprecisa, dado que no todos los medios se han mantenido como tal y no todos los artefactos arquitectónicos se han desarrollado como extemporáneos a la naturaleza. Más bien, los límites entre arquitectura y naturaleza se han diluido de manera considerable en las últimas décadas, siguiendo a veces antiguas estrategias en las que la arquitectura no se concebía en discontinuidad con su medio natural. Como consecuencia, podemos descubrir producciones ambiguas que dan lugar a potenciales clasificaciones de contenido ambivalente con profundas raíces en la tradición y en la historia, reforzando así el concep-
Figs. 10 y 11

Portada metálica a la Exposición Universal de 1900. París, Francia. Arquitecto, René Binet.

Fig. 12

Ciudad en el aire. Arquitecto: Arata Isozaki. 1961. El arquitecto, insatisfecho con el caos de Tokio, levantó una ciudad ordenada completamente separada de la primera que le servía de base, cuyas ramificaciones crecian desde megacolumnas centrales.

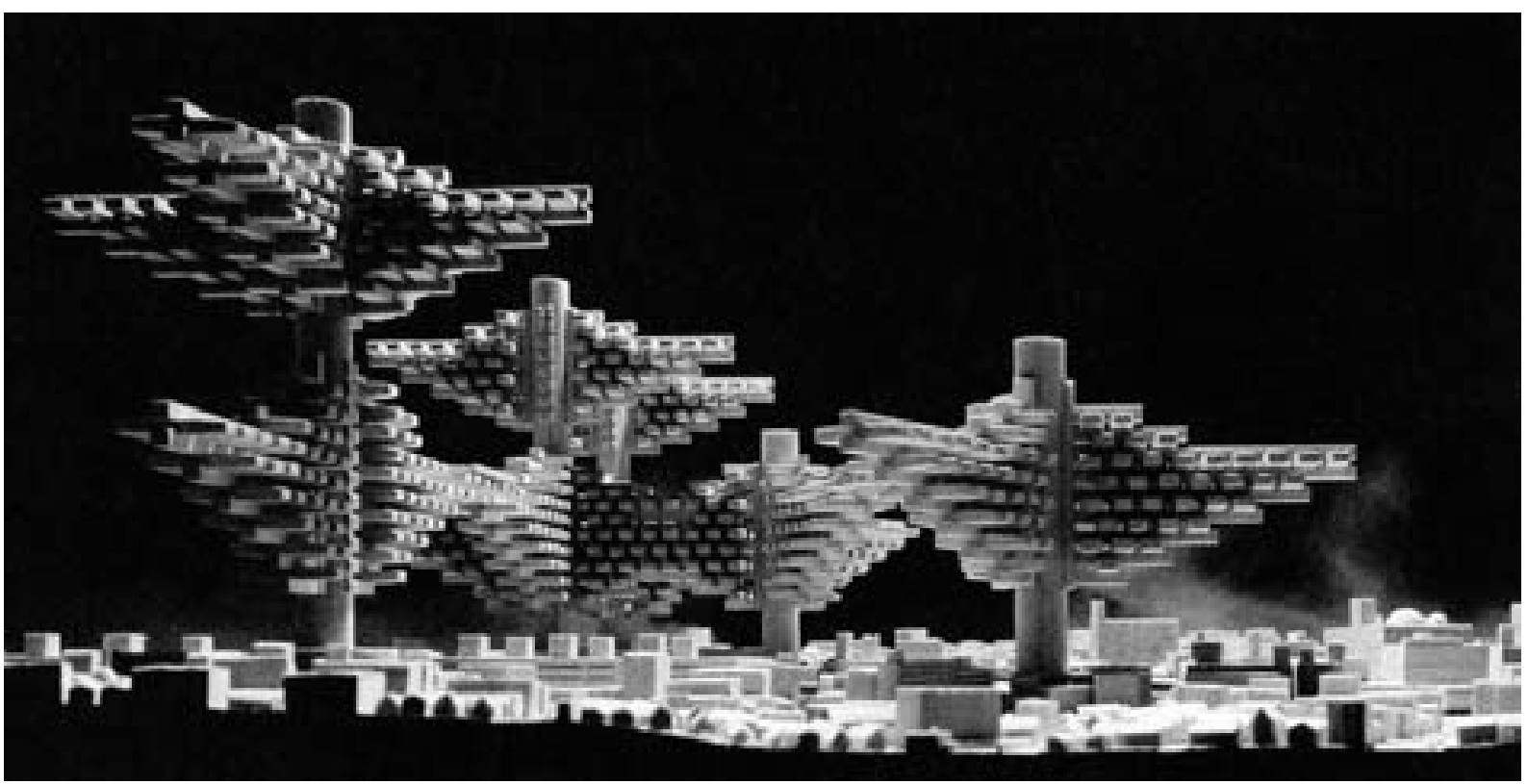


to de Regionalismo Crítico acuñado por Alex Tzonis y Liane Lefaivre en $1981^{18}$. El redescubrimiento de soluciones locales genuinas que conjugan la arquitectura realizada por el hombre y las condiciones naturales existentes pueden dar lugar una perspectiva crítica en el marco de una aproximación antropocénica al medio construido contemporáneo.

DEL CERRAMIENTO MASIVO A

LA MALLA ARTICULADA
Tras haber situado un cierto marco teórico e histórico en la aproximación a las relaciones entre naturaleza y arquitectura, podríamos diferenciar dos grupos generales de estrategias constructivas en arquitectura con orígenes en el medio natural: uno que genera espacios mediante estructuras cerradas con planos masivos y rígidos de materia, donde prevalece la presencia gravitacional de fuerzas de compresión; y otro que genera espacios a través del crecimiento de mecanismos abiertos o estructuras móviles que funcionan principalmente en tensión, en las que predominan los nudos y las articulaciones flexibles. Las primeras estructuras podrían calificarse de cerramientos, y constituirían soluciones materialmente continuas que se definen en gran medida por construcciones pesadas e inmóviles. Las segundas conforman estructuras ligeras que podrían calificarse de armazones, y se definen principalmente por una colección inestable y frágil de piezas interconectadas ${ }^{19}$.

Los cerramientos definen espacios de límites escalables que producen experiencias cuya forma construida podría calificarse de opaca, pesada, oscura e impenetrable, separada del mundo exterior con el cual no guarda conexión visual. La fuerza de estas estructuras pertenece al ámbito de lo terminado y estático. Los cerramientos masivos y continuos que caracterizan estas arquitecturas plantean un lenguaje gravitacional que enlaza conceptual y físicamente al observador con la tierra que sirve de base mediante una serie de fuerzas verticales. Estos espacios transmiten una experiencia de peso, dimensión y concreción a los sentidos, y se relacionan con la gravedad de la masa mediante un perímetro que se construye por acumulación de materia. Los espacios encerrados en estas arquitecturas son generalmente percibidos como experiencias panópticas unificadas.

Los armazones, por el contrario, constituyen arquitecturas de límites inestables e impredecibles que dan forma a una experiencia espacial indefinida y ambigua ${ }^{20}$. Un armazón de este tipo puede ser atravesado con facilidad por la luz y la vista, implicando interior y exterior en un mismo proceso perceptivo. Esta cualidad caracteriza la continuidad de su sección arquitectónica y proporciona conexiones cruzadas entre ambos lados, a diferencia de los espacios encerrados entre bordes continuos, que tienden a bloquear todo contacto visual ${ }^{21}$. En los armazones el espacio se rompe en sucesivos solapamientos en los que las uniones entre las partes tienen lugar en el aire intersticial. La arquitectura de los armazones es ligera, difusa e imprecisa, y su percepción se refiere a la levedad de la materia disgregada que parece quedar en suspensión. Los armazones perfilan un espacio de carácter discontinuo, inestable y cambiante, sobre el que el profesor José Antonio Sosa escribe: "[Los armazones] facilitan la función y la organización sin orden aparente [...], sin límites precisos y con una condición de borde permeable"22. Ambas aproximaciones estructurales, cerramientos y armazones, son conceptual y físicamente antagónicos, y constituyen dos operaciones arquitectónicas 


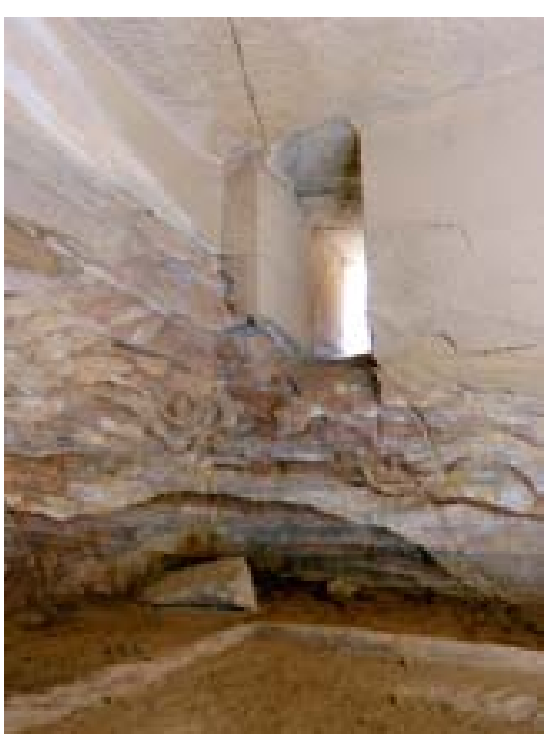

13

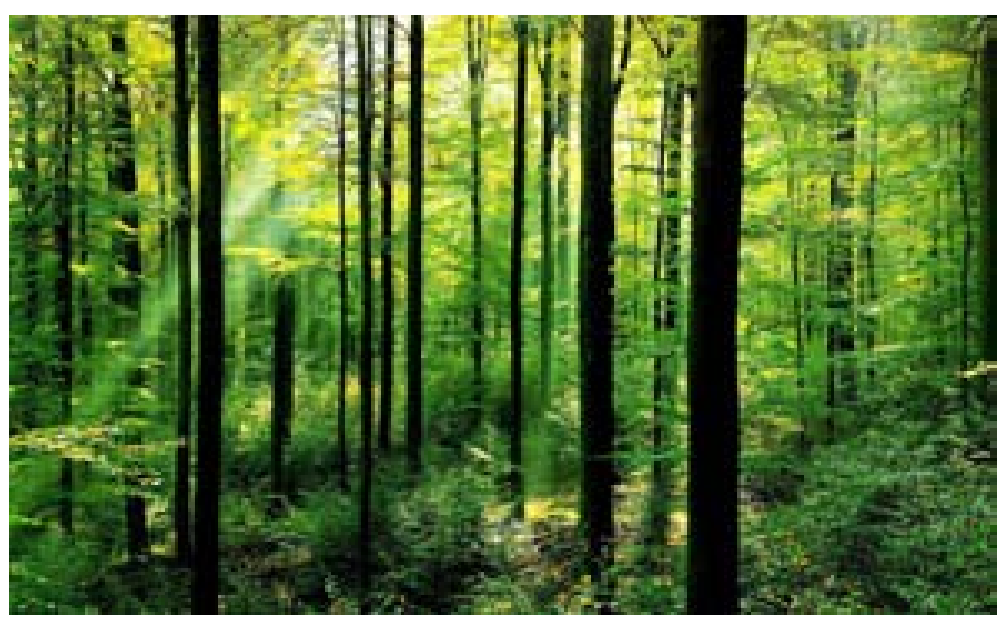

14 diferenciadas: una construcción de volumen cerrado alude a un estado de ocultación y compacidad, mientras que una construcción en malla sugiere un estado de apertura y disolución. En sendos casos, el estudio de las estructuras naturales y sus modos de formación y de crecimiento han sido reinterpretados ampliamente en términos artificiales. Si buscamos ejemplos en la naturaleza para ilustrar las diferencias, podríamos establecer una comparación entre el cerramiento y la cueva y el armazón y el bosque, respectivamente.

La cueva puede ser considerada como un espacio primitivo modelado por una estructura continua que se relaciona con el exterior únicamente mediante aberturas estereotómicas (stereo: piedra; tomos: cortar) (fig. 13). Las conexiones con el exterior tienen lugar a través de pequeños cortes o agujeros en la masa que contiene al espacio. La cueva actúa como un cerramiento que queda completado y consolidado por la masa circundante. Su estructura dibuja con claridad la diferencia entre materia y aire, y entre espacio interior y espacio exterior, conformando un lugar definitivo donde los sentidos buscan la relación explícita con el otro lado a través de la intencionalidad de los huecos.

El bosque, por el contrario, proporciona el contrapunto a la cueva como un modelo estructural abierto y cambiante que participa de las acciones que tienen lugar más allá de sus límites. La trama espontánea de las ramas del árbol da forma a un armazón impredecible, visual y físicamente complejo, que determina las relaciones espaciales con el medio (fig. 14). El bosque es un lugar de percepciones no consolidadas que constituye sistemas complejos como resultado de la suma de una serie de condiciones variables. Ramas, hojas $u$ otros árboles producen un solapamiento de materia en capas con parámetros variables como el color, el movimiento o las formas de las hojas y las ramas, entre otras. La configuración natural de estos árboles resulta inevitablemente impredecible en la definición de sus contornos, y constituye un armazón dinámico y mecánicamente inestable. Las relaciones visuales y físicas que el bosque proporciona como estructura de crecimiento flexible están muy alejadas del estatismo explorado en el modelo anterior de la cueva.
Fig. 13 Ciudad Nabatea de Petra, Jordania.

Fig. 14

Interior de un bosque. 
El cerramiento estereotómico establece una estrategia de ocupación primaria que puede ser considerada una operación arquitectónica primitiva, mientras que el armazón tectónico parece operar bajo condiciones más complejas, cercanas a las de ciertos intereses contemporáneos. En este caso, estaríamos trabajando con sistemas capaces de incorporar parámetros adicionales en las relaciones espaciales. La cueva plantea una continuidad física del cerramiento pero una discontinuidad espacial entre interior y exterior, en la que las conexiones quedan bloqueadas por la continuidad de la masa. En esta situación, el observador queda vinculado al medio construido y es forzado a participar en la severidad arquitectónica en la cual queda inmerso. Sin embargo, el bosque se comporta de manera opuesta, y la discontinuidad física del armazón evidencia una continuidad espacial entre los diferentes lados, pues estos sistemas facilitan una permeabilidad transversal en lo visual y en lo físico. Estas cualidades liberan al observador de las ataduras físicas y lo vinculan por completo al espacio que le rodea a través de la red permeable de árboles en la continuidad que proporciona el aire. Los primeros implican una arquitectura impuesta en el medio natural, mientras que los segundos conllevan una arquitectura sometida al medio natural ${ }^{23}$.

NATURAL Y ARTIFICIAL: AMBIGÜEDADES ESTRUCTURALES

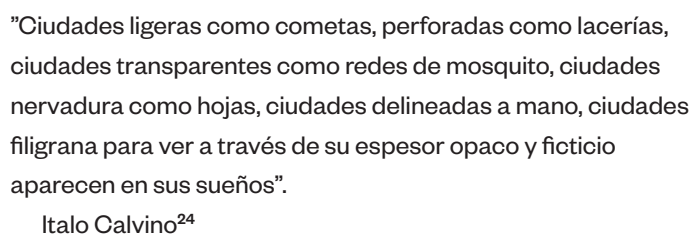

La línea que divide los grupos estructurales de lo natural y lo artificial no es siempre visible, sino imprecisa e intercambiable. Con objeto de ilustrar esta ambigüedad arquitectónica entre un crecimiento natural y una construcción artificial, podríamos acudir en primer lugar a la lectura de Eupalinos de Paul Valéry, en el momento preciso en que Fedro le dice a Sócrates que ha encontrado un objeto en la arena:

\footnotetext{
"Sócrates: [...] Su forma singular dejó todos mis pensamientos en suspenso. ¿Quién te hizo? pensé. No te pareces a nada conocido y, sin embargo, no careces de forma. ¿Eres un capricho de la naturaleza?

Fedro: ¿Y de qué materia estaba hecho?

Sócrates: De la misma materia que su forma: materia de duda”25.
}

La descripción que Fedro hace del ambiguo objeto hallado en la arena alude a su incierto e indiscernible origen natural o artificial de un modo similar a la exploración llevada a cabo por Haeckel sobre el origen poco claro de sus formas ilustradas a comienzos del siglo XX. Algunas cuestiones pueden resultar particularmente pertinentes en este punto. ¿Pierden todas las naturalezas manipuladas por la mano del hombre su esencia natural? ¿Tiene la "materia de duda" que da forma al objeto hallado en la arena por Fedro un origen natural o es un producto artificial? ¿Cuándo empieza uno a ser el otro?

Carece de sentido discutir sobre "arquitectura natural", pues toda arquitectura implica siempre un grado de manipulación física intencionada que la hace, en consecuencia, explícitamente artificial. Pero podríamos considerar a priori que una estructura es natural cuando su 
origen y desarrollo emergen directamente de fuentes naturales y carecen de modificaciones artificiales de relevancia; por otra parte, podemos calificar una estructura de artificial cuando está predominantemente alterada o producida por acción humana sobre la naturaleza. Sin embargo, el uso de la naturaleza como modelo en la manipulación del medio y, en particular, en la aplicación directa de estructuras vegetales con un grado reducido de manipulación física, podría conducir a una renovada discusión acerca de la distinción ambigua entre construcción artificial y construcción natural.

Al tomar la naturaleza como modelo, el hombre ha desarrollado dos aproximaciones a la manipulación del medio: una que reinterpreta la naturaleza de manera directa y produce una arquitectura naturalizada, y otra que explora el potencial directo de las fuentes naturales como medio para proponer nuevos espacios y estructuras, dando lugar a una naturaleza arquitectonizada. Mientras la primera afronta el riesgo de resultar literal en su solución final, los proyectos bajo estas premisas representan un conjunto recurrente de obras, pues su producción es visualmente inmediata y conceptualmente comprensible por una audiencia mayoritaria. La segunda, sin embargo, puede resultar notablemente menos habitual dado que sus aplicaciones se limitan a fuentes y medios puramente naturales, generando toda una serie de opciones inesperadas pero de mayor especificidad. Las arquitecturas naturalizadas tienen una presencia mayor como estrategia arquitectónica, mientras que las naturalezas arquitectonizadas tienen, por el contrario, limitaciones adicionales dadas las restricciones materiales per se, generando a menudo propuestas más restringidas. Las primeras operaciones conducen en su mayor parte a una aproximación orientada a la imagen final que transmite un mensaje preciso basado en la inspiración directa en las estructuras naturales, por lo que el paralelismo establecido entre la nueva construcción y su referente natural es notoriamente evidente. Como consecuencia, el resultado de estas estrategias generalmente expone una conexión literal con interpretaciones más o menos limitadas. Por el contrario, las segundas operaciones se enfocan en la dirección opuesta, produciendo una especie de anti-imagen y conforman un tipo de reorganización de las materias y estructuras naturales, resultando en medios naturales con intervenciones integradas. Podríamos considerar que las arquitecturas naturalizadas son notables por su efecto, mientras que las naturalezas arquitectonizadas tienden a desaparecer en un proceso de mímesis.

Arquitecturas naturalizadas: estrategias de efecto
Las arquitecturas naturalizadas tienen lugar cuando la ejecución de su diseño se enfoca de manera explícita a la imitación literal de la espontaneidad orgánica del crecimiento vegetal. Esta estrategia aparece en ejemplos en los que sus arquitectos han intentado recrear

una naturaleza que admiran o anhelan mediante la reproducción de estructuras de aspecto vegetal por medios artificiales, bien materiales, bien constructivos. Principalmente enfocada hacia lo representativo, podríamos decir que estas operaciones se calificarían de mecanismos de efecto, pues quedan determinados por la producción de una imagen final que exhibe potentes y comprensibles resultados visuale ${ }^{26}$. Estos casos quedan ilustrados con arquitecturas en las que lo tectónico emula 

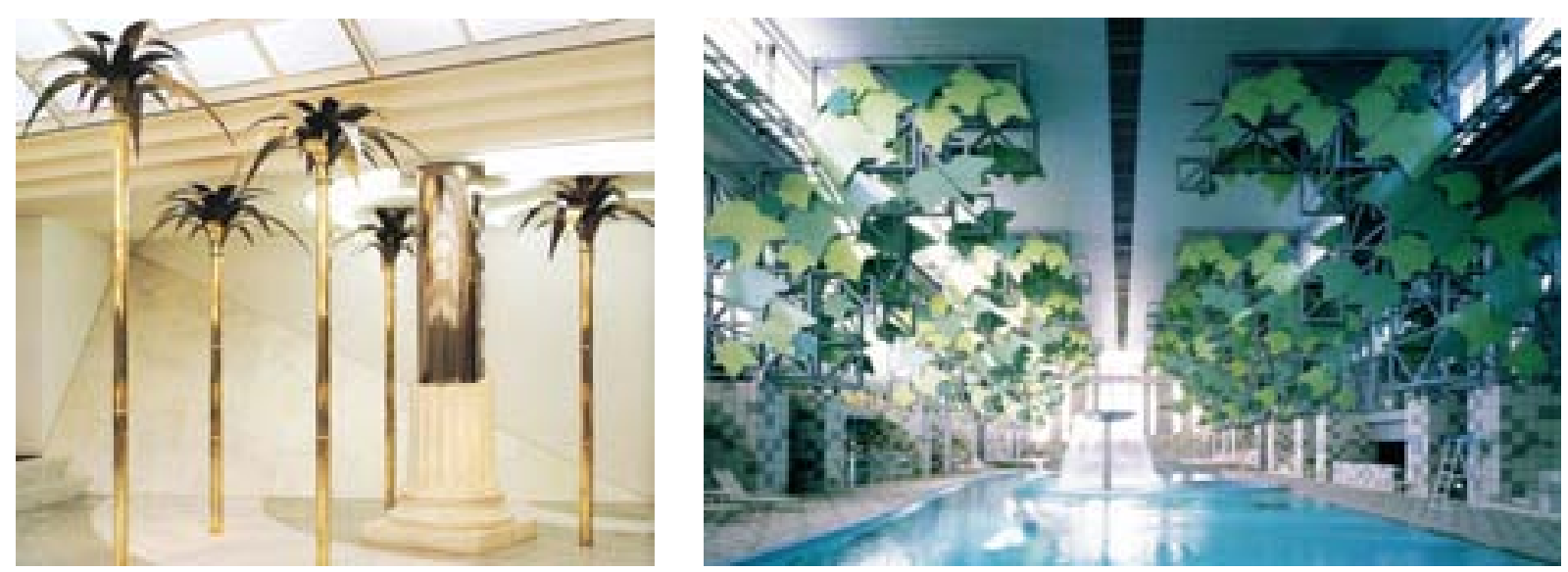

15

16

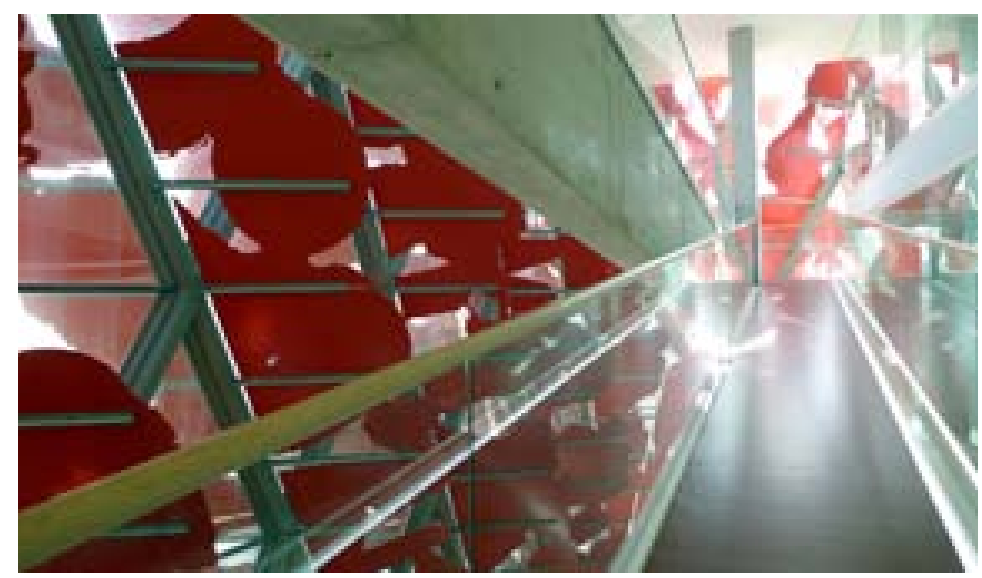

$$
17
$$
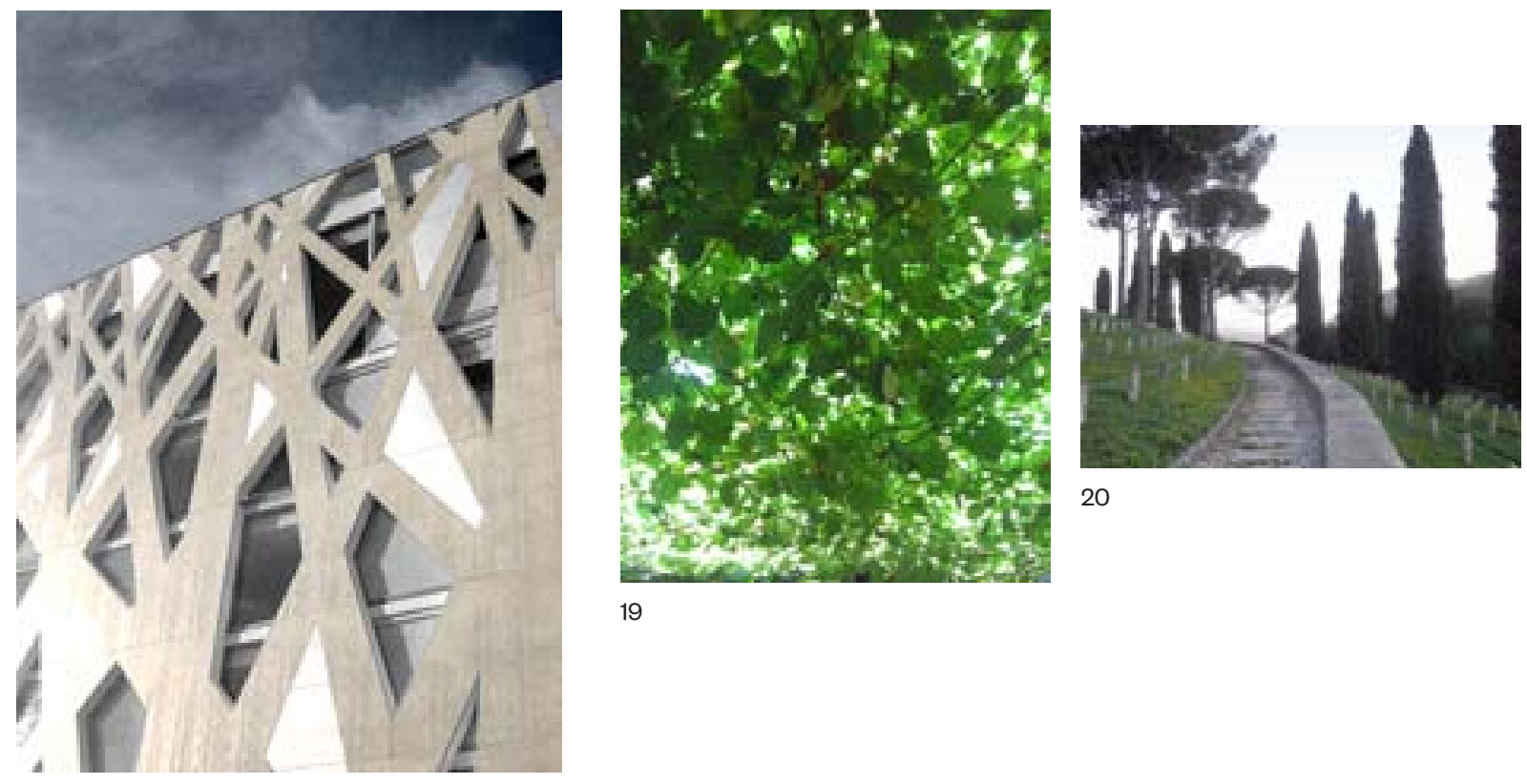

20 
una aproximación figurativa lista para ser entendida por el gran público, llegando incluso a ser mercantilizadas. Algunos de los trabajos que ejemplifican dicha intención podrían ser la sucursal de la agencia de viajes austríaca en Viena (1978) y el Centro Judío de Bienvenida (1979), de Hans Hollein (fig. 15); la piscina del SPA del hotel Mielmonte, en Nikko, Japón, obra de Venturi Scott Brown and Associates (1992-1997) (fig. 16); el edificio departamental para la Universidad Pompeu Fabra en Barcelona, obra de Juan Navarro Baldeweg (1996-2007) (fig. 17); o la propuesta para la estructura arbolada perimetral en la sede de Tod's en Omotesando, Tokio, por Toyo Ito (2002-2004) (fig. 18). Hollein recrea las cualidades exóticas en la agencia con una representación posmoderna del desierto mediante una serie de palmeras falsas, que no tienen otra misión que la de recrear la experiencia que puede ser adquirida en dicha agencia ${ }^{27}$. Venturi Scott Brown and Associates reproducen una falsa hiedra en el techo de la piscina del hotel; Navarro Baldeweg presenta una solución de fachada que muestra una vegetación abstracta en color rojo que funciona como brise-soleil; y Toyo Ito concibe su proyecto como un ejercicio unitario donde el artificio construido emerge como recreación de un mecanismo natural -un bosque de nueve árboles-. A pesar de que la condición tectónica desarrollada por Ito asume la función estructural del proyecto -algo que ni Hans Hollein introduce con sus palmeras, ni Venturi o Navarro con sus respectivas operaciones gráficas-, el diseño final de lto enfatiza la construcción como representación de una estructura arbórea, emulando un elemento natural que el arquitecto japonés admira profundamente. Más allá del grado de figuración en la explotación más o menos literal de la naturaleza como modelo, la vegetación y el árbol son utilizados como estrategias de efecto, enfatizando un ejercicio metafóri$\mathrm{co}-\mathrm{y}$ a veces irónico- de arquitectura naturalizada artificial.

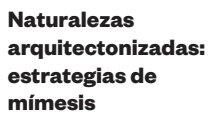

\begin{abstract}
Estos casos tienen lugar cuando formaciones estrictamente naturales son manipuladas en el tiempo y el espacio sin alterar su esencia material o estructural. Este tipo de soluciones podrían no considerarse arquitectura per se, sino una especie de formación natural
\end{abstract}

desnaturalizada o, más precisamente, una naturaleza arquitectonizada. Una alteración controlada en el crecimiento de estas formaciones ambiguas puede quedar ilustrada en ejemplos muy comunes tales como las parras que crecen en planos organizados por cables, formando marquesinas para proteger del duro sol en países como Grecia, España o Portugal, o la plantación intencionada de cipreses en línea generando una secuencia vertical imponente que flanquea los caminos mediterráneos a los cementerios como representación metafórica de incorruptibilidad e inmortalidad (figs. 19 y 20). Estos casos nos muestran cómo la manipulación o reorganización de estructuras naturales pueden oscilar entre estándares puramente prácticos, como se aprecia en los emparrados, a representaciones alegóricas que producen experiencias escenográficas, como las observadas en los cipreses. Estos son ejercicios de mímesis, en los que la reordenación o manipulación resultante no queda desligada del medio natural original, pero exhibe a la vez una innegable intención espacial. Estas operaciones quedan lejos de ser evidentes y, aunque su resultado sea el de un medio manipulado, su impacto no queda condicionado por la producción de una imagen sino que queda integrado por
Fig. 15

Agencia de viajes estatal. Viena, Austria. 1976-1979 (demolida 1987). Arquitecto: Hans Hollein.

Fig. 16

SPA. Hotel Mielmonte. Nikko Kirifuri. Nikko, Japón. 1992-1997. Venturi, Scott Brown and Associates.

Fig. 17

Edificio Departamental. Universidad Pompeu Fabra. Barcelona, España. Arquitecto: Juan Navarro Baldeweg. 2008.

Fig. 18

Sede de Tod's. Omotesando. Tokio, Japón. Arquitecto: Toyo Ito. 2004.

Fig. 19

Cubierta de emparrado. Sur de España.

Fig. 20

Cementerio alemán (Kriegsgräberstätt). Caira, Cassino, Italia. 


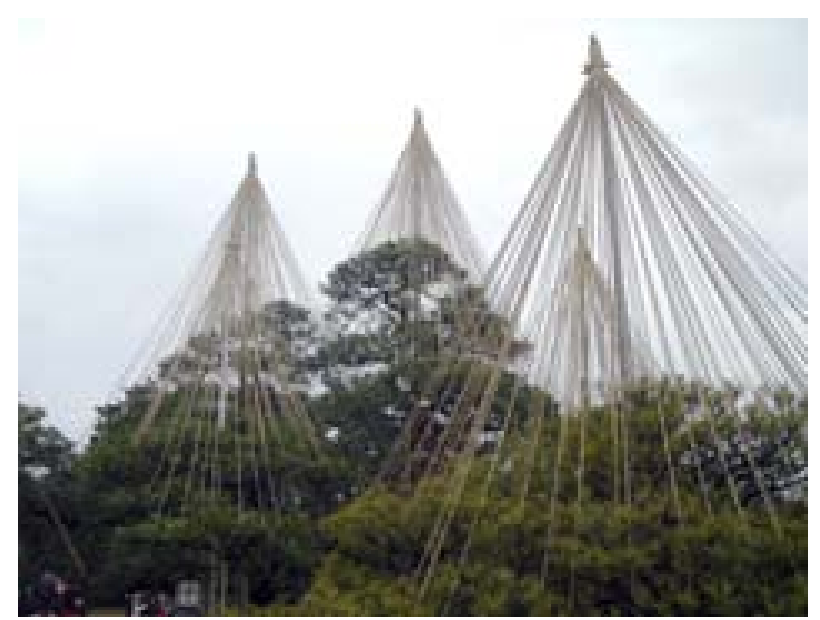

21

Figs. 21, 22 y 23

Yukitsuri. Jardín de Kenroku-en. Kanazawa, Japón.

Fig. 24

Yukitsuri. Jardín de Kenroku-en. Kanazawa, Japón. Proceso de montaje.

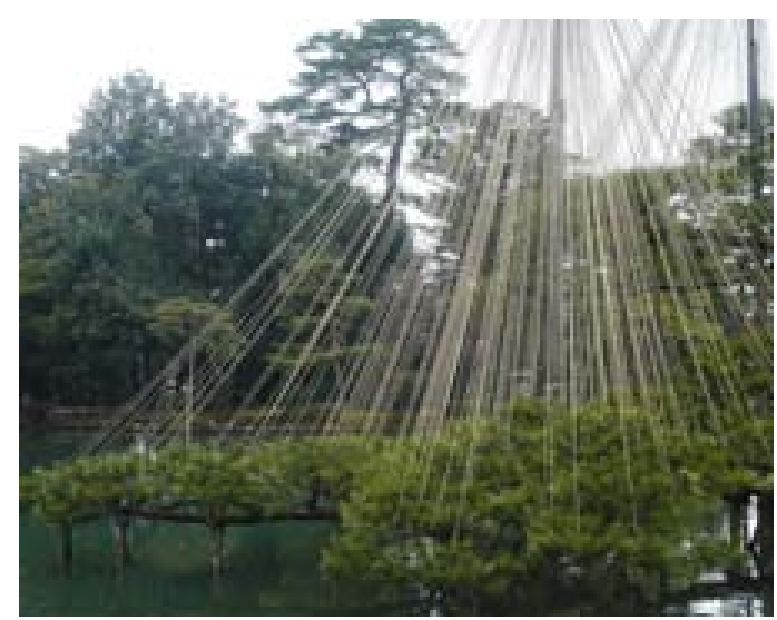

22 completo con el contexto natural existente sin ruptura alguna. Existe un componente artificial en la organización intencionada del crecimiento natural; sin embargo, el material y la estructura siguen perteneciendo al ámbito de los puramente natural. Los jardines tradicionales de Japón ofrecen un ejemplo oportuno a esta tesis. Sus naturalezas arquitectonizadas conservan una enorme afinidad con la cultura y la sensibilidad nacional, y nos permiten establecer en este punto un contexto geográfico y cultural coherente con el caso previo de Toyo lto ${ }^{28}$.

El jardín de Kenroku-en en la ciudad de Kanazawa, en la isla de Honshu, data del siglo XVI y puede ser considerado uno de los jardines más relevantes del período Edo en Japón (1603-1868). El jardín ocupa una extensión de casi una hectárea en la zona alta de la ciudad, cerca del castillo homónimo y no lejos del conocido Museo del Siglo XXI, obra de Kazuyo Sejima y Rye Nishizawa. El nombre Kenroku-en significa "el que tiene seis elementos", dado que los parámetros que conducen al paisaje perfecto son la espaciosidad, la tranquilidad, el artificio, la antigüedad, los cursos de agua y las vistas desde el propio jardín. Sin embargo, uno de los elementos más característicos está formado por el sistema conocido como yukitsuri, que literalmente significa colgantes de nieve. Dicho sistema se refiere a las estructuras de cuerda atadas en disposición cónica alrededor de los árboles con el fin de proteger sus ramas del peso excesivo por acumulación de nieve (figs. 21 y 22). La práctica de esta técnica en el jardín de Kenroku-en comenzó en el período Edo como una solución puramente funcional que prevenía la rotura de las ramas durante los meses de invierno, y ayudaba en la continuación de su crecimiento manipulado. Los cabos, junto con otros elementos auxiliares -similares a muletas- dan cobijo al árbol como elemento natural por excelencia, abrazando las ramas que se extienden más allá del tronco, y dirigiendo el crecimiento preciso del árbol.

De la aparente dimensión natural de este jardín, podrían destacarse dos aspectos en la relación entre las condiciones naturales y artificiales. En primer lugar, el concepto de jardín japonés en sí mismo, que es propuesto como un ejercicio de artificio natural como contraposición a un ejercicio de naturaleza artificial; en segundo lugar, los yukitsuri o pequeñas construcciones realizadas con bambú y cuerda como un sistema de andamiaje único cuya función es proteger la forma global de los árboles en consonancia con el diseño del paisaje. Los árboles del jardín 


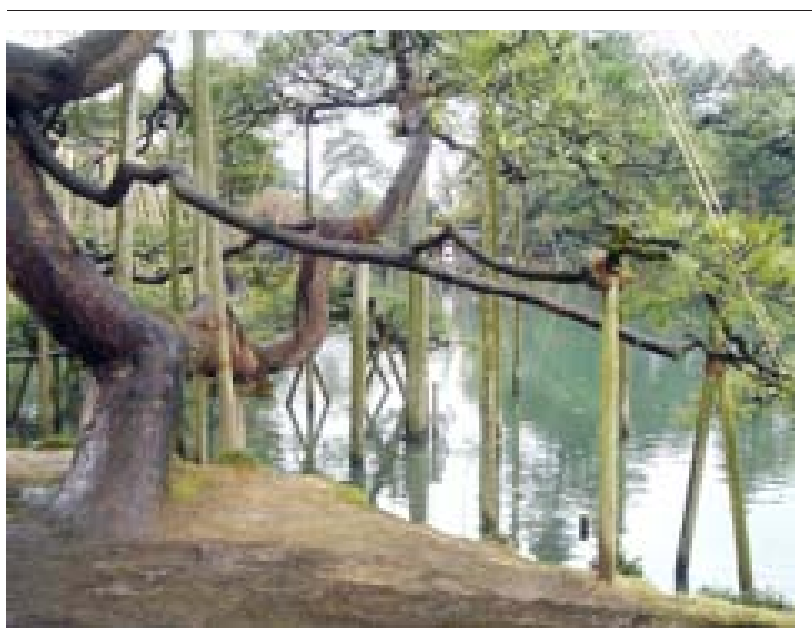

23

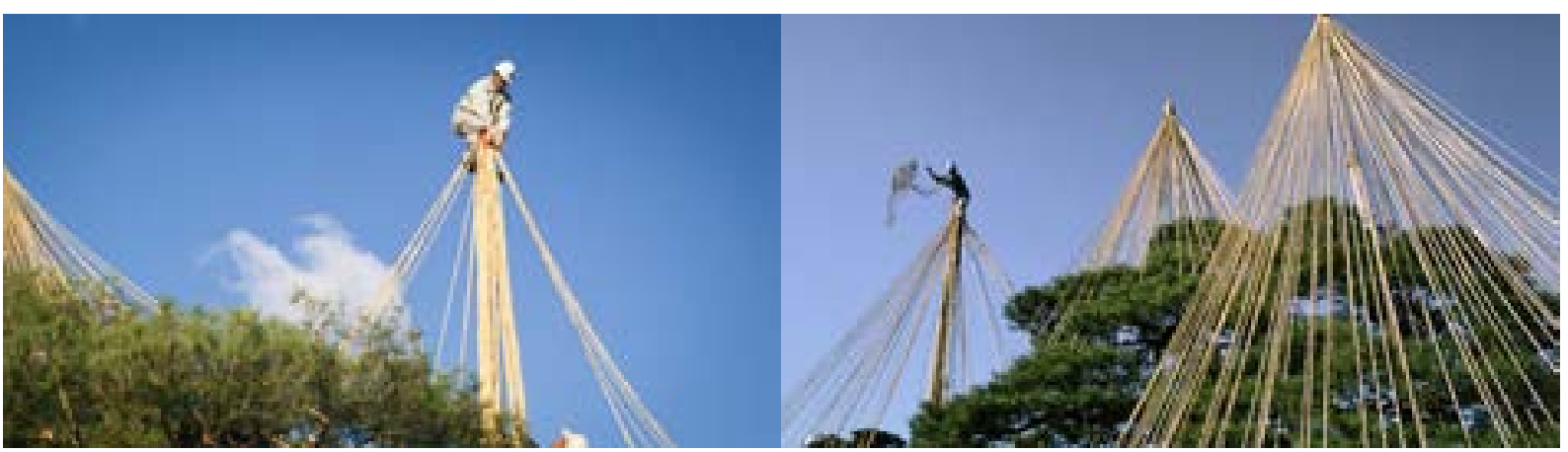

24

son obviamente naturales, pero son dispuestos con un orden y una ubicación premeditados, para a continuación ser controlados por cuerdas y apoyos que trabajan como estructuras auxiliares, proporcionando al árbol la forma final con la ayuda de la tenacidad y el tiempo. La tradición requiere que las ramas se transformen en un ejercicio de belleza artificial, y el crecimiento natural del follaje queda construido a un tiempo con la disposición puramente artificial de las cuerdas. Sin embargo, es la estructura complementaria del andamiaje la que en paralelo adquiere forma de árbol, generando conos de cuerda alrededor de cada árbol o apoyos verticales de bambú a modo de muletas para miembros inmóviles, anticipando las formas que los japoneses buscan para las ramas de sus árboles (figs. 23 y 24). El jardín de Kenroku-en se concibe como una intervención global en la que el crecimiento natural es tratado como materia para un trabajo artificial, donde la operación artificial adquiere connotaciones naturales. El resultado es un paisaje natural-artificial ambiguo que se manipula de manera mimética a base de combinar las ramas tratadas de manera artificial y las cuerdas y muletas de manera natural.

Las mismas estrategias parecen haber inspirado la reciente propuesta de Jin Young Song y Miguel Guitart para un jardín temporal en el International Garden Festival de 2014 en los jardines de Métis, en Québec, Canadá. El diseño giraba en torno a la idea de unos postes de bambú tratados de manera explícitamente artificial en una disposición en planta en trama ortogonal, con pequeñas plantas en los 
Figs. 25,26 y 27

Jin Young Song / Miguel Guitart. Propuesta para Jardín de Métis. Canadá. 2014. Vista general de maqueta, detalle de la generación de la superficie y vista interior. extremos superiores de los postes que crecían cubriendo dichos postes verticalmente, difuminando en el tiempo la presencia de la disposición en retícula (figs. 25 y 26). La memoria dice:

\footnotetext{
"Los postes de bambú plantean un jardín flotante [...] cuya condición queda definida por la superficie virtual que cambia con el tiempo en función del crecimiento de las plantas en el extremo superior de los postes. El visitante accede al jardín a través de la disposición permeable de postes, cuya percepción se modifica según se avanza hacia el interior. El extremo superior de los postes conforma una superficie virtual que desciende hacia el centro del jardín y asciende hacia su perímetro. En consecuencia, el visitante termina por hallarse rodeado por una superficie [virtual] que se configura con los extremos de los postes verticales y el perímetro ligeramente más alto que una persona. La experiencia conduce a la consciencia del movimiento propio alrededor de la superficie virtual de la vegetación en lo alto en un proceso de introspección. El jardín de postes de bambú proporciona la percepción de un jardín dentro de un jardín, así como la oportunidad de concentrarse en la superficie envolvente que los extremos superiores configuran alrededor del visitante"29.
}

Los extremos de los postes no son, sin embargo, el final, sino el comienzo de una nueva forma de vida: los postes se cortan y se vacían en el lado superior para albergar una pequeña porción de tierra en la que crecerán las plantas en el tiempo. La vegetación crece en los extremos y envuelve el bambú. Según pasa el tiempo, todos los postes florecen, transformando así el esqueleto de la estructura inicial del bambú en una construcción verde en vertical que rodea intencionadamente al visitante de forma cambiante según el paso de las estaciones. En consecuencia, la percepción en el tiempo es crítica en el jardín de bambú propuesto: lejos de ser una experiencia estática, el jardín trata de significar los cambios en el tiempo en un diálogo ambiguo entre lo natural y lo artificial (fig. 27).

Según crecen las plantas, las percepciones del olor, el sonido y la visión cambian. El diseño evoluciona de manera dramática conforme los postes desnudos florecen, creando una suerte de superficie verde que flota sobre el plano del suelo levemente inclinado. El jardín de postes genera un espacio arquitectónico cuya configuración se alcanza mediante la transformación de la retícula artificial en un escenario natural de crecimiento vertical. La experiencia resultante refuerza la naturaleza arquitectonizada y la arquitectura naturalizada que ocurren de manera simultánea. El empleo de bambú remite a una nueva sensibilidad en el uso de materiales sostenibles en la arquitectura contemporánea. La exploración de técnicas de construcción y materiales que enfaticen un entendimiento mutuamente respetuoso y enriquecedor entre lo artificial y lo natural queda demostrado aquí por la organización explícitamente artificial de los postes de bambú como medio para configurar un nuevo tipo de jardín a través de sus cualidades tanto naturales como artificiales.

Estrategias como esta parecen abrir de forma inequívoca nuevos caminos en el modo en que la naturaleza es incorporada a los procesos de diseño y construcción, partiendo de las propiedades mismas de la forma y estructura naturales, y promoviendo una ambigüedad en el discurso entre lo natural y lo artificial. Dichas estructuras, la artificialmente natural y la naturalmente artificial, se funden en una única operación mediante una suerte de extraordinaria simbiosis de doble ambigüedad. 


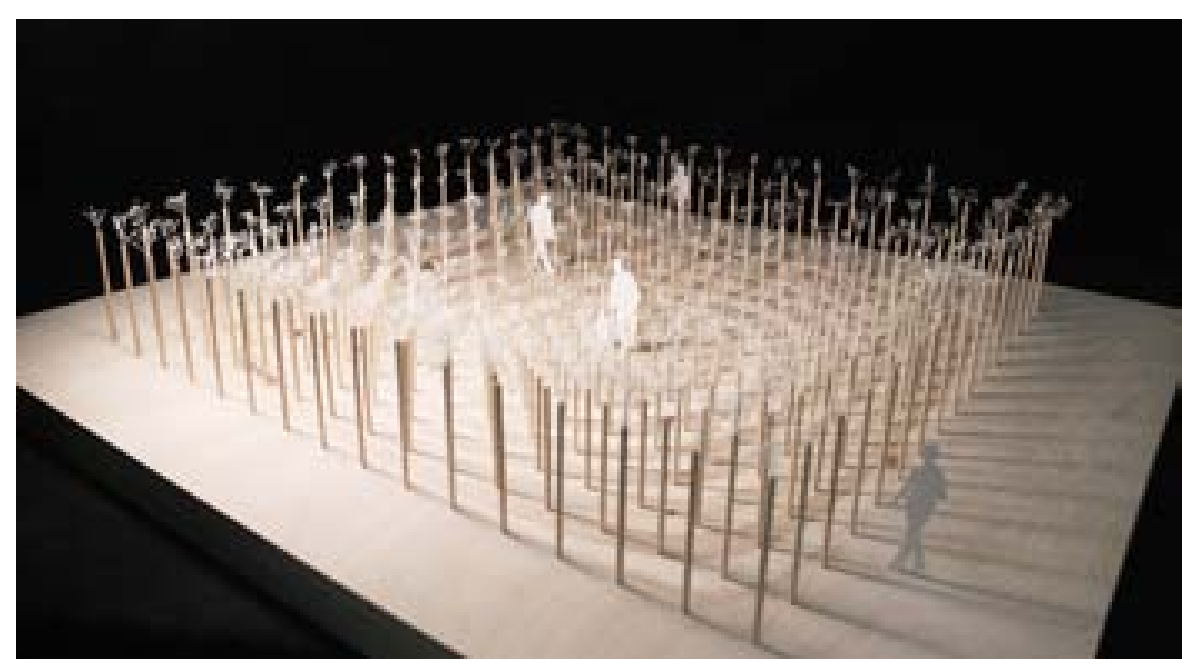

25

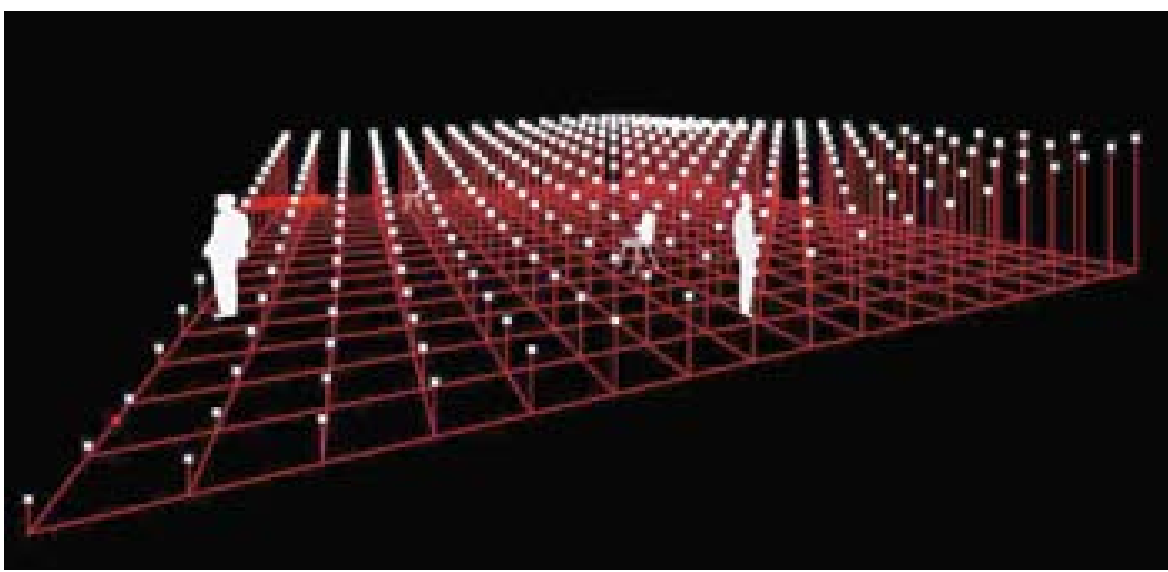

26

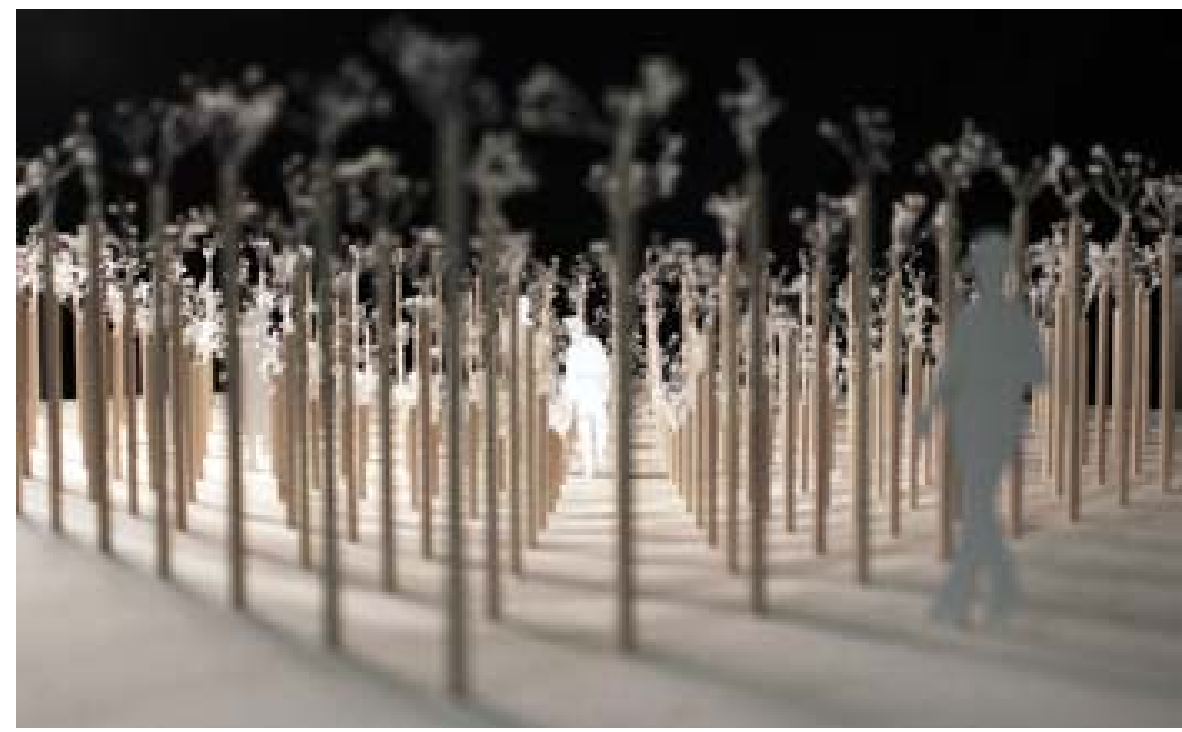




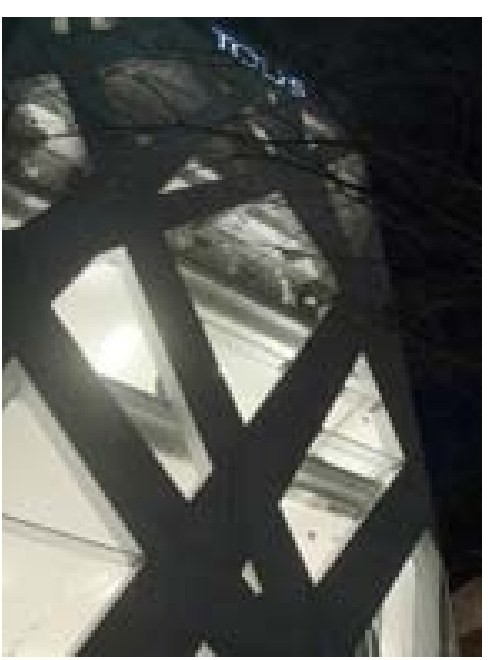

28

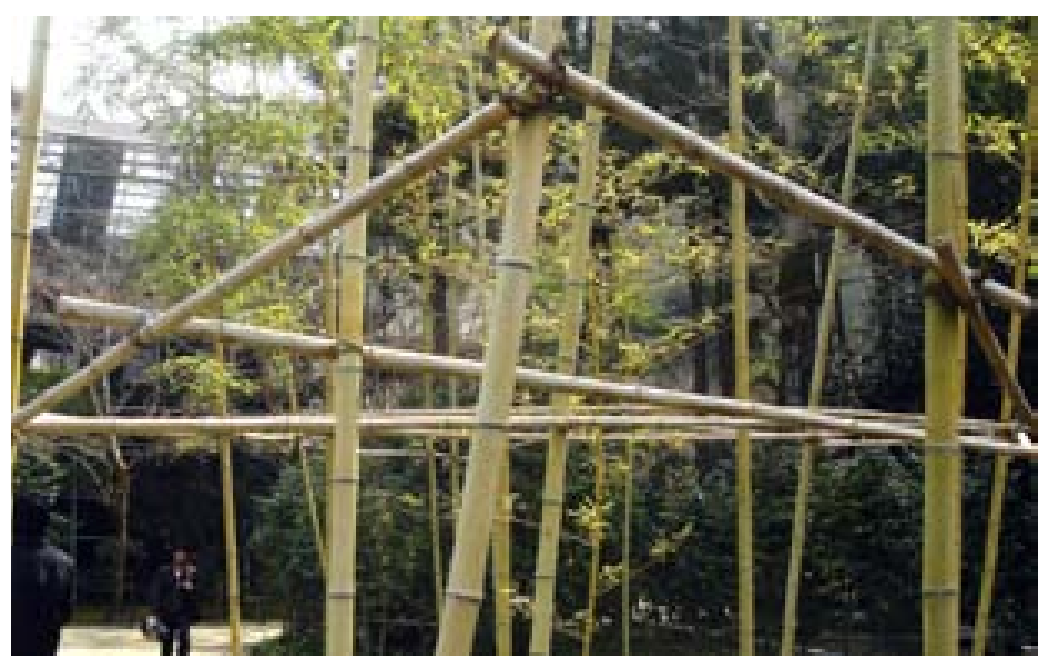

29

\section{CONCLUSIONES: EL ENTORNO} MANUFACTURADO

\begin{abstract}
"La naturaleza tiene un sentido distinto del tiempo.
El tiempo es amplio en el paisaje, mientras que en la ciudad es condensado, igual que el espacio de la ciudad". Peter Zumthor ${ }^{30}$
\end{abstract}

A través de la tradición y la historia, el arquitecto ha tomado la naturaleza de manera consciente como modelo de referencia, de la que resultaba posible extraer dos aproximaciones posibles al diseño arquitectónico: por una parte, una estrategia predominante que reinterpreta la naturaleza para producir una arquitectura naturalizada, en la que la forma de las estructuras vegetales es abstraída, dando lugar a un resultado visual muy efectivo, con técnicas materiales y procedimientos constructivos que resultan ajenos a su esencia material; y por otra parte, una estrategia que recurre a recursos naturales para manipular y transformar estructuras naturales de manera artificial, configurando naturalezas arquitectonizadas en las que las estructuras materiales básicas se mantienen enteramente naturales.

Mientras los primeros modelos corren el riesgo de conformar resultados literales con aproximaciones que son excesivamente directas o evidentes, constituyen sin embargo una línea de diseño con una presencia recurrente debido a una forma de producción que es inmediatamente icónica y, en consecuencia, conceptualmente comprensible (fig. 28); su ejecución material no está necesariamente condicionada por un sistema constructivo particular que se aparta del modelo original; más bien, la construcción y el proceso estructural quedan abiertos a diferentes soluciones que son enteramente artificiales -desligadas de procedimientos o condicionantes naturales-. El segundo modelo, sin embargo, puede resultar una opción menos común y de enorme potencial, y da lugar a todo un abanico de soluciones inesperadas, pues su aplicación queda principalmente limitada a una producción puramente natural y a medios paisajísticos con importantes limitaciones materiales y constructivas (fig. 29).

Aunque ambos grupos han estado presentes de una manera u otra en la historia de la arquitectura, podríamos decir que las arquitecturas naturalizadas han tenido una mayor presencia como producto arquitectónico, con ejemplos como las propuestas de Hans Hollein
Fig. 30

Jardín de Kenroku-en. Kanazawa, Japón.
Fig. 28 Sede de Tod's. Omotesando. Tokio, Japón. Arquitecto: Toyo Ito. 2004.

Fig. 29

Construcción de bambú en jardín. Japón. 
para la agencia de viajes en Austria, de Venturi Scott Brown para el SPA del hotel Mielmonte, de Juan Navarro Baldeweg para la universidad Pompeu Fabra, o de Toyo Ito para la sede de Tod's en Omotesando. Las naturalezas arquitectonizadas tienen, por el contrario, mayores limitaciones y son a menudo resultado del trabajo de manipulación que queda mimetizado con la naturaleza con la que opera -por ejemplo, la aplicación de los yukitsuri en Kanazawa, como hemos podido observar (fig. 30). Si el primer modelo estructural apunta principalmente a una producción dirigida explícitamente desde la imagen final, el segundo modelo opera en la dirección opuesta enfocada hacia una anti-imagen mediante un ejercicio de desaparición en el medio existente. Los primeros son notables por su efecto y presencia iconográfica, mientras los últimos desaparecen en un proceso de integración por mímesis. Aunque ambas operaciones están basadas en estrategias naturales, en el contexto antropocénico de la transformación del medio, podría debatirse sobre la manipulación de la naturaleza y la ambigüedad en el proceso por el cual lo natural se transforma en artificial y viceversa. Se podría incluso concluir que la opción del trabajo directo con arquitectura natural podría asumirse como un camino de potencial creciente dadas sus características de renovada ingenuidad y lógica aplicación por sus beneficios económicos, medioambientales y paisajísticos ${ }^{31}$. Esta estrategia de trabajo puede ser por tanto susceptible de experimentar un creciente interés por parte de profesionales y diseñadores causada principalmente por la creciente conciencia medioambiental y el renovado interés por el trabajo manufacturado, en el que el proceso, la materia y el medio son actores principales en el marco de nuestro mundo manufacturado. RA

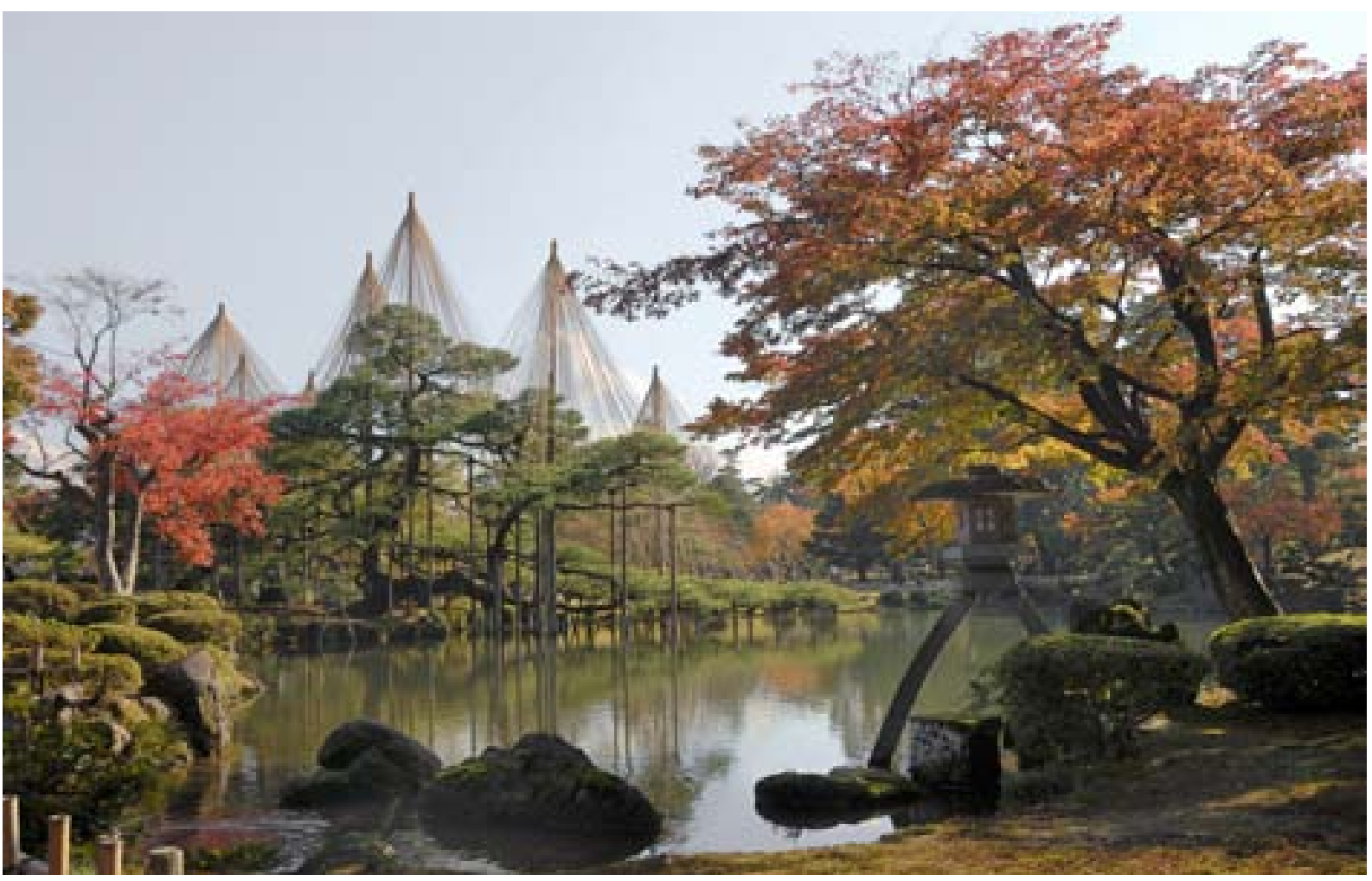


01. THOREAU, Henry David, $A$ Week on the Concord and Merrimack Rivers (1849), New York, Literary Classics of the United States, 1985, p. 258.

02. ZUMTHOR, Peter, "Does Beauty Have a Form?", Thinking Architecture, Basel, Birkhäuser, 1998, p. 73.

\section{BERGDOLL, Barry, "Nature's}

Architecture: The Quest for the Laws of Form and the Critique of Historicism", Nature Design. From Inspiration to Innovation, Angeli Sachs ed., Zurich, Lars Müller/ Museum für Gestaltung Zürich, 2007, pp. 46-59.

04. Barry Bergdoll indica la fuente como: WAENERBERG, Annika, Urpflanze und Ornament:Pflanzenmorphologische Anregungen in der Kunsttheorie und Kunst von Goethe bis zum Jugendstil, Commentationes Humanarum Litterarum 98 Helsinki, 1992, en BERGDOLL, Barry, op. cit.

05. ADLER, Friedrich, "De Bauschule zu Berlin von K. F. Schinkel" (1869), reimpresión en: Schinkel zu Ehren: Festreden, 1846-1980, Berlin, Julius Posener, 1981, pp. 101-20. En BERGDOLL, Barry, op. cit.

06. Karl Friedrich Schinkel, citado en: PESCHKEN, Goerd, ed., Karl Friedrich Schinkel: Das Architektonische Lehrbuch, Munich, 1979, p. 50. En BERGDOLL, Barry, op. cit.

07. Schinkel recibió una copia de dicho libro cuando visitó a Goethe en Weimar en 1816. Véase: BERGDOLL, Barry, op. cit.

08. Johann Wolfgang von Goethe, Metamorphosis of Plants, sec. 3, trad: Agnes R. Arber, en: Goethe's Botany: The Metamorphosis of Plants (1782), Waltham, MA., 1946, en BERGDOLL, Barry, op. cit.

09. K. F. Schinkel, citado en: PESCHKEN, Goerd, op. cit., p. 50. En: BERGDOLL, Barry, op. cit.

10. Alexander von Humboldt, en: Cosmos, vol. 1, p. 41. Para Semper, "igual que la naturaleza en su infinita variedad [...] renueva continuamente los mismos esqueletos al modificarlos mil veces de acuerdo con las etapas de formación alcanzadas, [...] las obras de arte también se basan en ciertas formas estándar condicionadas por ideas primigenias, aún permitiendo una infinita variedad de fenómenos de acuerdo con las necesidades particulares que les afectan". Véase SEMPER, Gottfried, "Prospectus, Comparative Theory of Building" (1852) en, MALLGRAVE, Harry Francis; HERRMANN, Wolfgang, Gottfried Semper: The Four Elements of Architecture, p. 170. Como explica Bergdoll, a finales de los años 1840 Semper había esbozado un prospecto para una Vergleichende Baulehre, (Teoría comparativa de la edificación) modelado por las conferencias Cosmos, de Alexander von Humboldt. En: BERGDOLL, Barry, op. cit.

11. E. E. Viollet-le-Duc, "Style", Dictionnaire Raissoné de l'architecture..., vol. 8, París, 1858-1870, pp. 477-501. Véase traducción al inglés, BERGDOLL, Barry, ed., Viollet-le-Duc: The Foundations of Architecture; Selections from the Dictionnaire Raisonné, con introducción de B. Bergdoll. Trad. Kenneth D. Whitehead, New York, G. Braziller, 1990, p. 235.

12. Constant-Dufeux era uno de los pedagogos más celebrados a mediados del siglo XIX, asociado tanto con la École des Beaux-Arts como con el romanticismo en arquitectura.

13. "Entre 1855 y 1860 , el alemán Karl Krumholz, influido por Gottfried Semper entre otros, comenzó a trabajar en París en la elaboración de sus propias ilustraciones de plantas, empezando con la publicación de su Composition des fleures d'après nature.. à l'usages des artistes industriels in 1859. Su obra Das vegetable Ornament, de 1880 y uno de sus últimos trabajos, sirvió como una fuente fundamental para gran parte del Jugendstil. [...]". Véase, BERGDOLL, Barry, op. cit.

14. Bergdoll indica que la investigación reciente ha mostrado posibles conexiones entre Binet y Sullivan. Véase Marie-Laure Crosnier-Lecomte, "René Binet", en: ThiemeBecker/Vollmer Gesamtregister: Register zum Allgemeine Lexikon der bildenden Künstler von der Antike bis zur Gegenwart und zum Allgemeinen Lexikon des XX. Jahrhunderts, Munich y Leipzig, 1996, En: BERGDOLL, Barry, op. cit.

15. Gustave Geffroy, prefacio a Esquisses décoratives, por René Binet, París, 1902-03, p. 1. Véase: BERGDOLL, Barry, op. cit.

16. Explicado por Gustave Geffroy, amigo personal de Binet. Véase: BERGDOLL, Barry, op. cit.
17. Ibid.

18. Véase: TZONIS, Alex; LEFAIVRE, Liane, "The Grid and The Pathway. An introduction to the work of Dimitris and Suzana Antonakakis", Architecture in Greece, n. 15, Atenas, 1981, Véase: FRAMPTON, Kenneth, "Towards a Critical Regionalism: Six Points for an Architecture of Resistance", Labour, Work and Architecture. Collected Essays on Architecture and Design, Londres, Phaidon Press, 2002.

19. Ambos términos son explicados por Miguel Guitart en su texto La piel profunda, Madrid, Ediciones Asimétricas, 2014.

20. En relación con el concepto de inestabilidad, destacan los textos del profesor llya Prigogine (1917-2003), notable Físico y Químico belga y Premio Nobel, cuya investigación sobre estructuras disipativas, sistemas complejos e irreversibilidad son de gran interés. Véase: PRIGOGINE, llya, "Why Thermodynamics?" y "Structural Instability and Biochemical Evolution", en, Modern Thermodynamics. From Heat Engines to Dissipative Structures, New York, John Wiley \& Sons, 2015.

21. Véase: GUITART, Miguel, "Atravesando los huecos de la piel", La piel profunda, Madrid, Asimétricas, 2015, p. 37.

22. SOSA DÍAZ-SAAVEDRA, José Antonio, "Armazones", Transfer, n. 5, Valencia, Universidad de Valencia, 2003, pp. 7-10.

23. Las soluciones arquitectónicas en geografías templadas se benefician de las estrategias masivas que facilitan el aislamiento térmico pasivo con costes altamente eficientes. La futura evolución de las estructuras en armazón conduce, como sus equivalentes naturales, a arquitecturas técnicamente más complejas con soluciones más ligeras debido a un uso más eficiente de los materiales, que se adaptan a los cambios en las relaciones espaciales y los parámetros externos variables. A causa de la inflexibilidad material de los primeros modelos constructivos y de la flexibilidad de los segundos, el creciente conjunto de parámetros que intervie en la producción arquitectónica de hoy hace más proclive la consideración de soluciones en malla o armazón más que las de sistemas de envolventes cerradas.

24. CALVINO, Italo, Las ciudades invisibles, Milán, Giulio Einaudi, 1972. 


\section{Referencias bibliográficas}

25. VALÉRY, Paul, Eupalinos or The Architect, (1921), en: Paul Valéry, Dialogues, Bollingen Series XLV 4, Princeton, NJ, Princeton University Press, 1989, Trad. al inglés de William McCausland Stewart.

26. En relación con la distinción tectónica entre lo representativo y lo ontológico, los textos del profesor Kenneth Frampton resultan altamente recomendables. Véase: FRAMPTON, Kenneth, "Introduction: Reflections on the Scope of the Tectonic" y "Postscriptum: The Tectonic Trajectory. 1903-1994", Studies in Tectonic Culture: The Poetics of Construction in Nineteenth and Twentieth Century Architecture, Cambridge, MA, The MIT Press, 2001.

27. En claro paralelismo con la cabaña decorada (decorated shed), de Robert Venturi y Denise Scott Brown, término acuñado en el libro Learning From Las Vegas, 1972.

28. Véase: BOGNAR, Botond, "The Japanese Order of Things", Kochuu. Arquitectura Japonesa. Influencia y Origen, Barcelona, Fundación Arquia - Caja de Arquitectos. 2003; y GROPIUS, Walter, "Architecture in Japan", Perspecta, Vol. 3, Cambridge, MA, The MIT Press, 1995, pp. 8-2, 79-80.

29. http://dioinno.com/floating-gardenevolving-surface, $y$ http://miguel-guitart.com

30. ZUMTHOR, Peter, "Architecture and Landscape", Thinking Architecture, Basel, Birkhäuser, 1998, p. 96. Trad. del autor.

31. La búsqueda de nuevos valores es quizá más evidente en culturas que no han sido esencialmente alteradas y permanecen en un estado genuino, principalmente en África, América del Sur y Asia. Esta idea era compartida por Bernard Rudofsky en su publicación más notable. Véase: RUDOFSKY, B., Architecture Without Architects: A Short Introduction to Non-pedigreed Architecture, Garden City, New York, Doubleday Company Inc, 1965, Como parte de la presente conversación, podríamos atender al concepto del arrière-garde, opuesto al avante-garde, mencionado por Kenneth Frampton como contraestrategia con el objetivo de reforzar el regionalismo crítico con el fin de producir una arquitectura localmente enraizada y conectada con su propia historia y emplazamiento.
- ALLEN, Stan, "Field Conditions", Points and Lines Diagrams and Projects for the City, New York, Princeton Architectural Press, 1985.

- APARICIO, Jesús, EI Muro, Palermo, Textos de Arquitectura y Diseño, Universidad de Palermo, 2000.

- BERGDOLL, Barry, “Nature's Architecture: The Quest for the Laws of Form and the Critique of Historicism", Nature Design. From Inspiration to Innovation, Angeli Sachs ed., Zurich, Lars Müller/ Museum für Gestaltung Zürich, 2007, pp. 46-59.

- BOGNAR, Botond, "The Japanese Order of Things", Kochuu. Arquitectura Japonesa. Influencia y Origen, Barcelona, Fundación Arquia - Caja de Arquitectos, 2003.

- CALVINO, Italo, Las ciudades invisibles, Milán, Giulio Einaudi, 1972.

- FERNÁNDEZ-GALIANO, Luis, Fire and Memory. On Architecture and Energy, Cambridge, MA., The MIT Press, 2000,

- FRAMPTON, Kenneth, "Introduction: Reflections on the Scope of the Tectonic"; y "Postscriptum: The Tectonic Trajectory. 1903-1994", Studies in Tectonic Culture: The Poetics of Construction in Nineteenth and Twentieth Century Architecture, Cambridge, MA., The MIT Press, 2001.

- FRAMPTON, Kenneth, "Towards a Critical Regionalism: Six Points for an Architecture of Resistence", Labour, Work and Architecture. Collected Essays on Architecture and Design, Londres, Phaidon Press, 2002.

- GROPIUS, Walter, "Architecture in Japan", Perspecta, Vol. 3 Cambridge, MA., The MIT Press, 1995.

- GUITART, Miguel, “Las Piedras del Pasado", Arquitectura COAM, Vol. 359, Madrid, COAM, 2009.

- GUITART, Miguel, La piel profunda, Madrid, Ed. Asimetricas, 2015.

- MALLGRAVE, Harry Francis; HERRMANN, Wolfgang, Gottfried Semper: The Four Elements of Architecture and Other Writings, NY Cambridge University Press, 1989.

- MUMFORD, Lewis, Technics and Civilization, New York, Harcourt, Brace \& Company, Inc., 1934.
-PRIGOGINE, Ilya, “The Philosophy of Instability", Futures: The Journal of Policy, Planning and Futures Studies, Vol. 21, n. 4 1989.

-PRIGOGINE, llya, "Why Thermodynamics?"; y "Structural Instability and Biochemical Evolution", Modern Thermodynamics. From Heat Engines to Dissipative Structures, New York, John Wiley \& Sons, 2015.

- RUDOFSKY, Bernard, Architecture Without Architects: A Short Introduction to Nonpedigreed Architecture, Garden City, New York, Doubleday Company Inc, 1965.

-SECKLER, Eduard, "Structure, Construction, and Tectonics", Structure in Arts and in Science, G. Kepes, ed, New York, Braziller, 1965.

- SEMPER, Gottfried, The Four Elements of Architecture, 1851.

- SOSA dÍAZ-SAAVEDRA, José Antonio, "Armazones", Transfer, n. 5, Valencia, Universidad de Valencia, 2003.

- THOREAU, Henry David, A Week on the Concord and Merrimack Rivers, 1849, New York, Literary Classics of the United States.

- TZONIS, Alex; LEFAIVRE, Liane, "The Grid and The Pathway. An introduction to the work of Dimitris and Suzana Antonakakis", Architecture in Greece, n. 15, Atenas, 1981.

- TZONIS, A.; LEFAIVRE, L., Critical regionalism: Architecture and ldentity in a Globalized World, New York, Prestel, 2003.

- VALÉRY, Paul, "Eupalinos or The Architect", (1921), Paul Valéry, Dialogues, Bollingen Series XLV 4, Princeton, NJ., Princeton University Press, 1989. Traducido por William McCausland Stewart.

- VENTURI, Robert; SCOTT-BROWN, Denise, Learning From Las Vegas, 1972.

- ZUMTHOR, Peter, "Does Beauty Have a Form?", Thinking Architecture, Basilea, Birkhäuser, 1998.
RA. Revista de Arquitectura Núm. 20 - 2018 P. $130-151$ 